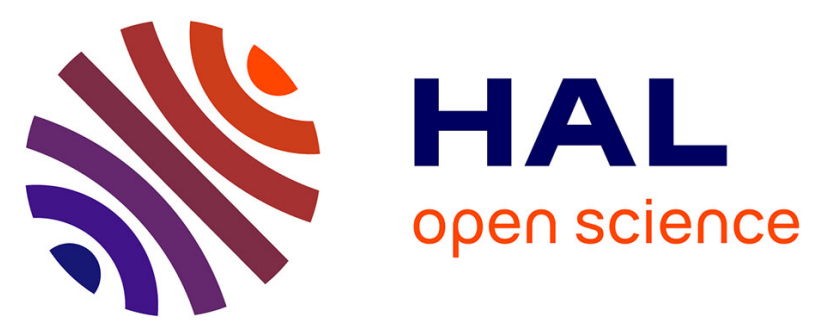

\title{
An integrative taxonomic framework for the study of the genus Ciona (Ascidiacea) and description of a new species, Ciona intermedia
}

Francesco Mastrototaro, Federica Montesanto, Marika Salonna, Frédérique Viard, Giovanni Chimienti, Egidio Trainito, Carmela Gissi

\section{To cite this version:}

Francesco Mastrototaro, Federica Montesanto, Marika Salonna, Frédérique Viard, Giovanni Chimienti, et al.. An integrative taxonomic framework for the study of the genus Ciona (Ascidiacea) and description of a new species, Ciona intermedia. Zoological Journal of the Linnean Society, 2020, 10.1093/zoolinnean/zlaa042 . hal-02861027

\section{HAL Id: hal-02861027 https://hal.science/hal-02861027}

Submitted on 8 Jun 2020

HAL is a multi-disciplinary open access archive for the deposit and dissemination of scientific research documents, whether they are published or not. The documents may come from teaching and research institutions in France or abroad, or from public or private research centers.
L'archive ouverte pluridisciplinaire HAL, est destinée au dépôt et à la diffusion de documents scientifiques de niveau recherche, publiés ou non, émanant des établissements d'enseignement et de recherche français ou étrangers, des laboratoires publics ou privés. 
Doi: 10.1093/zoolinnean/zlaa042

An integrative taxonomy framework for the study of the genus Ciona (Ascidiacea) and the description of the new species Ciona intermedia

Francesco Mastrototaro ${ }^{1}$, Federica Montesanto ${ }^{1 *}$, Marika Salonna ${ }^{2}$, Frédérique Viard ${ }^{3}$, Giovanni Chimienti ${ }^{1}$, Egidio Trainito ${ }^{4}$, Carmela Gissi ${ }^{2,5, *}$

${ }^{1}$ Department of Biology and CoNISMa LRU, University of Bari "Aldo Moro" Via Orabona, 4 70125 Bari, Italy

2 Department of Biosciences, Biotechnologies and Biopharmaceutics, University of Bari "Aldo Moro", Via Orabona, 4 - 70125 Bari, Italy

${ }^{3}$ Sorbonne Université, CNRS, Lab. Adaptation \& Diversity in Marine Environment (UMR 7144), Station Biologique, Roscoff, France

${ }^{4}$ Villaggio I Fari, Loiri Porto San Paolo, Olbia-Tempio, Italy

${ }^{5}$ IBIOM, Istituto di Biomembrane, Bioenergetica e Biotecnologie Molecolari, CNR, Bari, Via Amendola 165/A - 70126, Bari, Italy

*corresponding authors 


\begin{abstract}
The genus Ciona Fleming, 1822 is an interesting "taxonomic case" since its evolutionary history and taxonomy have not been yet completely resolved. This study presents new findings, describing specimens of a non-identified Ciona species collected along the North-eastern coasts of Sardinia (Tyrrhenian Sea, Mediterranean Sea). Applying an integrative taxonomic approach, based on the joint examination of morphological and molecular traits, we identified these specimens as a new species, Ciona intermedia. Morphological comparisons and habitat peculiarities first revealed that these Ciona specimens have intermediate characters compared to those of other Ciona species. Then, the molecular characterization (based on three mitochondrial regions: two already used for discriminating Ciona cryptic species and a newly developed one) confirmed that our specimens could not be assigned to any previously molecularly-characterized species. Noteworthy, both molecular phylogenetic reconstructions and morphological data clearly indicated $C$. intermedia as a sister clade of Ciona edwardsi Roule, 1884. Our findings add further complexity to the Ciona taxonomy, underlying the importance of an integrative taxonomic approach for the study of this still enigmatic genus and of its evolutionary history.
\end{abstract}

Keywords: Ciona, Ascidian, new species, Mediterranean Sea, mitochondrial genes, DNA barcode 


\section{Introduction}

The genus Ciona Fleming, 1822 includes several species used as model organisms in various research fields, from evolutionary developmental biology to chordate evolution (Millar, 1953; Dehal et al., 2002; Cañestro et al., 2003; Satoh et al., 2003). Its suitability as model organism is due to anatomical and molecular features of this genus such as the large size, the transparency of the tunic, the macroscopic internal anatomy, the easily detected reactions to external stimuli (Millar, 1953) and the small compact genome as well as by the availability of powerful experimental tools for molecular studies (Lemaire, 2011). More recently, this genus has also become a case study for ecological studies (Procaccini et al., 2011, Zhan et al., 2015), notably because two of these members, namely Ciona intestinalis (Linnaeus, 1767) and Ciona robusta Hoshino \& Tokioka, 1967 (formerly known as C. intestinalis type $\mathrm{B}$ and $C$. intestinalis type A, respectively) have been recognized invasive species in several regions at a worldwide level (see Supplementary Material in Bouchemousse et al., 2016a). Nevertheless, this genus represents a real "taxonomic case", since it is characterized by debated assignment at order level, strong difficulties in delineation and delimitation of the different species, and a complex evolutionary history. Indeed, the genus Ciona is currently placed in the order Phlebobranchia based on the presence of a large pharynx with inner longitudinal vessels (Monniot, 1991). In the past, it was included in the order Aplousobranchia (Kott, 1990, 2005) on the basis of its vanadium oxidation state (Hawkins et al., 1983) and of the regenerative role of its epicardial tissue (Kott, 1990). More recently, some molecular phylogenetic reconstructions supported the sister relationship of the genus Ciona to Aplousobranchia (Turon \& López-Legentil, 2004; Shenkar et al., 2016), although sometimes with an unstable positioning (see discussion in Shenkar et al., 2016).

As for the difficulties in species delineation, for a long time (Berrill, 1950) several Ciona species were synonymized with the type species $C$. intestinalis, until, in the early 2000's, molecular studies indicated the existence of a surprisingly high genetic divergence among specimens of $C$. intestinalis from distant geographic localities (Suzuki et al., 2005; Caputi et al., 2007; Iannelli et al., 2007; Nydam \& Harrison, 2007, 2010; Zhan et al., 2010; Sato et al., 2012). These findings led first to the description of $C$. intestinalis sensu lato as a complex of four cryptic species, named from $\mathrm{A}$ to $\mathrm{D}$, and then to the in-depth morphological analyses revealing that $C$. intestinalis type A is C. robusta, while C. intestinalis type B corresponds to C. intestinalis (Brunetti et al., 2015; Pennati et al., 2015). In addition, in sympatric areas, no introgression has been reported between the two species, proving the existence of reproductive barriers between the two taxa (Bouchemousse et al., 2016b, 2016c; Malfant et al., 2018). Thus, the current knowledge indicates that C. robusta and C. intestinalis are clearly distinguishable by the morphology of both adults and larvae, as well as by their genetic background and global distribution. On the contrary, Ciona $\mathrm{spC}$ and $\mathrm{spD}$ still lack morphological diagnostic characters and can be currently identified only through molecular analyses (Nydam \& Harrison, 2007, 2010; Zhan et al., 2010; Brunetti et al., 2015). Another peculiar case is represented by the Ciona roulei Lahille, 1890. As for the nomenclature, we need to clarify that the original binomial of this species was Ciona roulii Lahille, 1890, and that Brunetti et al., (2015) considered the binomial Ciona roulei as an "Incorrect Subsequent Spelling" (ICZN, 1999 art 33.3) introduced by Hartmeyer (19091911) and Harant \& Verniéres (1933) without a clear justification. On the other hand, the C. roulii binomial was clearly created by Lahille to homage Roule (author of many ascidian species from 1883 to 1887), thus it can be considered an inadvertent misspelling (ICZN, 1999 art 32.5). Moreover, the C. roulei binomial was in prevailing usage by all subsequent authors (ICZN, 1999 art 33.3.1) (i.e., Harant \& Vernières, 1933). Therefore, here we choose to maintain the spelling roulei. Interestingly, mitochondrial phylogenetic analyses could not distinguish between $C$. roulei and C. intestinalis and 
the two taxa hybridize with high rate of success in both directions, displaying survival and growth rates similar to those found in the respective intra-species crosses (Malfant et al., 2018). Therefore, further in-depth investigations, integrating different types of data and different methodologies, are needed for confirming/excluding the taxonomic validity of $C$. roulei. It should be also noticed that, within the genus Ciona, the usage of the biological species concept should be carefully examined. For instance, in vitro crosses and first generation hybrids can be produced among accepted species, such as C. intestinalis and C. robusta (Sato et al., 2014; Bouchemousse et al., 2016c; Malfant et al., 2018), two taxa that introgressed in the past (Roux et al., 2013). Later on, studies of natural populations showed that hybridization is not followed by successful introgression (Bouchemousse $e t$ al., 2016b), suggesting the existence of reproductive barriers between the two species in the wild. On the contrary, Ciona edwardsi Roule, 1884 showed a complete reproductive isolation from the species C. intestinalis, C. roulei and C. robusta (Lambert et al., 1990; Malfant et al., 2018). These casestudies show the complexity of the evolutionary history and speciation processes in this genus that can obscure complicated taxonomy and systematics studies. Altogether, these results point to the Ciona genus as a complex taxonomic group that needs to be studied according to an integrative taxonomy approach (Padial et al., 2010). In fact, the intricate evolutionary history and the possible presence of still ongoing speciation events requires the combination of different types of data and the usage of different methodologies for the species delineation.

This study reports the identification along the North-eastern coasts of Sardinia of several specimens of the Ciona genus with unexpected (i.e., not described previously) features. An integrative taxonomy approach has revealed that these specimens belong to a new species, Ciona intermedia, that is here described in detail by morphological, ecological and molecular traits. Furthermore, molecular phylogenetic reconstructions of the genus Ciona based on three mitochondrial regions, have allowed identifying the species $C$. edwardsi as the closest to $C$. intermedia. Altogether, our data provide an important contribution to the knowledge of the evolutionary history of this genus for which the species delineation still requires further clarifications.

\section{Material and methods}

\section{Sampling and morphological analysis}

Seven specimens of Ciona sp. were photographed and manually collected by SCUBA diving near Olbia (Sardinia, Tyrrhenian Sea, Italy) at a depth of 3-5 m in July 2014. The sampling area was mainly characterized by calcareous algae, large solitary ascidians belonging to the genera Phallusia and Pyura, and small colonial ascidians like Symplegma brakenhielmi (Michaelsen, 1904) (Mastrototaro et al., 2019). Specimens of Ciona sp. were collected from shady sites, such as crevices of the rocks and under the pebbles. Five specimens were directly preserved in ethanol $99 \%$ for molecular investigations. The other specimens were narcotized with menthol crystals in seawater and then preserved in a 5\% formaldehyde solution in seawater for morphological analyses. In the relaxed specimens the test was removed, and the body was coloured with Mayer's hemalum solution for detailed investigations. We considered numerous morphological characters (consistency of tunic, morphology of siphons, number and distribution of body muscles, structure of the pharynx, shape of stomach and gonads) as well as some ecological characteristics of the specimens (occurrence in light or shady sites). 
Ciona sp. specimens from Olbia were morphologically compared to specimens of C. edwardsi, C. intestinalis, and C. robusta of the private collection of the Laboratory of Zoology of F. Mastrototaro (available on request; see Supplementary Table S1).

\section{Molecular analyses}

Total DNA of the three Ciona sp. specimens preserved in ethanol (labels ' $\mathrm{CR}$ ', ' $\mathrm{Ca}$ ' and ' $\mathrm{Cb}$ ' in Supplementary Material Tables) was extracted from muscle tissue using a modified CTAB method (Hirose \& Hirose, 2009). DNA from two C. roulei and three C. edwardsi specimens, sampled at Banyuls-sur-Mer (France), were also analysed. These C. roulei and C. edwardsi DNAs were obtained as part of a former study on experimental crosses within the Ciona genus (Malfant et al. 2018), during which the specimen identification was made by those authors based on morphological criteria, i.e., the external morphology, the spermiduct and gonoduct features, and the larvae (see data in the Supplementary Material of Malfant et al., 2018). The experimental crosses and the molecular analyses performed on those C. roulei and C. edwardsi specimens in Malfant et al., (2018) and in an ongoing genetic (nuclear-based) study (M. Malfant, E. Pante, C. Daguin-Thiébaut, C. Roby \& F. Viard, in preparation) matched the expectations based on the morphological identifications.

Using the primer pairs reported in Table 1, three mitochondrial $(\mathrm{mt})$ regions were amplified:

- a fragment of the cox1 gene about $1.2 \mathrm{~kb}$ - long, named COI-1.2kb, containing the $650 \mathrm{bp}$-long region widely used as a reliable DNA barcode;

- a fragment comprising the cox2 (cytochrome oxidase subunit 2) and cob (cytochrome b) genes, named $\mathrm{x} 2 \mathrm{cb}$;

- a fragment, named x3n1, encompassing the three genes cox3 (cytochrome oxidase subunit 3), trnK (tRNA-Lys) and nad1 (NADH dehydrogenase subunit 1), and two non-coding spacers. This fragment was originally identified and used by Iannelli et al., (2007) as a mt region able to distinguish $C$. intestinalis (formerly known as C. intestinalis type B) from C. robusta (formerly known as C. intestinalis type A), and then it was demonstrated to be able to distinguish also spC and spD (Zhan et al., 2010).

The COI-1.2kb fragment was amplified in all specimens (three Ciona sp., two C. roulei and three $C$. edwardsi), while $\mathrm{x} 3 \mathrm{n} 1$ was amplified in the three Ciona $\mathrm{sp}$. specimens and in only one representative of C. roulei and C. edwardsi. The three analysed Ciona sp. had identical COI-1.2kb and x3n1 sequences. Finally, x2cb was amplified in one specimen for each of the three considered species (Ciona sp., C. roulei and C. edwardsi).

The COI-1.2kb fragment was amplified with the high fidelity PrimeStar HS DNA polymerase (Takara Bio Inc.) in a $25 \mu$ reaction volume containing: $1 \mathrm{X}$ reaction buffer with $1 \mathrm{mM}$ final concentration of $\mathrm{MgCl} 2$ (Takara Bio Inc.), $0.2 \mathrm{mM}$ of each dNTP, $0.3 \mu \mathrm{M}$ of each primer and 1.25 Units of PrimeStar HS DNA polymerase (Takara Bio Inc.). Amplification conditions were: 30 cycles with denaturation for $10 \mathrm{~s}$ at $98^{\circ} \mathrm{C}$, annealing for $15 \mathrm{~s}$ at $46-52^{\circ} \mathrm{C}$ (depending on the specimen), extension for 2 min at $72^{\circ} \mathrm{C}$; a final elongation step of $5 \mathrm{~min}$ at $72^{\circ} \mathrm{C}$.

Amplifications of the $\mathrm{x} 2 \mathrm{cb}$ fragment were performed according to long-range PCR protocol, since the frequent gene order rearrangements typical of the ascidian mt genome (Gissi et al., 2010) made it impossible to predict a priori the distance between the cox2 and cob genes in the studied Ciona taxa. Therefore, amplification of the $\mathrm{x} 2 \mathrm{cb}$ fragment was carried out with the high fidelity LA Taq DNA polymerase (Takara Bio Inc.) at the following conditions: an initial denaturation for $1 \mathrm{~min}$ at $94^{\circ} \mathrm{C}$, then 30 amplification cycles with denaturation for $10 \mathrm{~s}$ at $98^{\circ} \mathrm{C}$, annealing for $5 \mathrm{~s}$ at $50^{\circ} \mathrm{C}$, extension for $12 \mathrm{~min}$ at $68^{\circ} \mathrm{C}$; a final elongation step of $10 \mathrm{~min}$ at $72^{\circ} \mathrm{C}$. The reactions were carried out in a final 
volume of $25 \mu$ containing: $1 \mathrm{X}$ reaction buffer with $2.5 \mathrm{mM}$ final concentration of $\mathrm{MgCl}_{2}$ (Takara Bio Inc.), $0.4 \mathrm{mM}$ of each $\mathrm{dNTP}, 0.2 \mu \mathrm{M}$ of each of the two primers, and 1.25 Units of LA Taq DNA polymerase (Takara Bio Inc.).

The $\mathrm{x} 3 \mathrm{n} 1$ fragment was amplified with the DreamTaq polymerase (Thermo Fisher Scientific) in a final volume of $25 \mu$ containing: $1 \mathrm{X}$ reaction buffer with $2 \mathrm{mM}$ final concentration of $\mathrm{MgCl}_{2}(\mathrm{Thermo}$ Scientific), $0.2 \mathrm{mM}$ of each $\mathrm{dNTP}, 0.5 \mu \mathrm{M}$ of each of the two primers, and 1.25 Units of DreamTaq polymerase. The amplification conditions were: an initial denaturation for $3 \mathrm{~min}$ at $95^{\circ} \mathrm{C}$, then 30 amplification cycles (denaturation for $30 \mathrm{~s}$ at $95^{\circ} \mathrm{C}$; annealing for $30 \mathrm{~s}$ at $50{ }^{\circ} \mathrm{C}$; extension for $2 \mathrm{~min}$ at $72^{\circ} \mathrm{C}$ ) followed by a final elongation step of $5 \mathrm{~min}$ at $72^{\circ}$.

All obtained amplicons were purified with the DNA Clean\&Concentrator kit (Zymo Research), and directly sequenced according to the Sanger method at the Microsynth AG (Switzerland) or Eurofins Genomics (Germany). Sequence quality check and assembly were carried out with Geneious ver. 5.5.7.2 (http://www.geneious.com; Kearse et al., 2012). All sequences were deposited at the ENA database (European Nucleotide Archive), and their accession numbers are reported in Supplementary Tables S2, S3, S4.

For comparative analyses, homologous sequences of the genus Ciona were searched in the NCBI non-redundant nucleotide database (nr-nt db, at 1st February 2019) by Blastn (Altschul et al., 1990), using as query our Ciona sp. sequences. Concerning cox1, we analysed a final dataset consisting of: representative sequences of C. robusta and C. intestinalis included in Malfant et al., (2018); three sequences of Ciona $\mathrm{spC}$ and Ciona $\mathrm{spD}$ from another yet unpublished study (M. Malfant, E. Pante, C. Daguin-Thiébaut, C. Roby, F. Viard, in preparation); all other Ciona species whose sequences were available in $\mathrm{nr}-\mathrm{nt} \mathrm{db}$. The analysed sequences of cox1, $\mathrm{x} 2 \mathrm{cb}$ and $\mathrm{x} 3 \mathrm{n} 1$ are listed in Supplementary Table S2, S3 and S4, respectively.

Phylogenetic analyses were performed separately for the three $\mathrm{mt}$ regions. Sequences were aligned by hand or with MAFFT (Katoh et al., 2002), preserving the codon structure of the protein-coding genes. The cox 1 final alignment was 1575 bp long (with 737 ungapped sites in $87 \%$ of the sequences) and consisted of 54 Ciona sequences plus a sequence of Clavelina lepadiformis (Müller, 1776) used as outgroup (see Supplementary Table S2). The x2cb final alignment was 1127 bp long (with 1078 ungapped sites) and consisted of 9 Ciona sequences plus 5 Aplousobranchia species as outgroups (see Supplementary Table S3). The x3n1 final alignment was 676 bp long (with 502 ungapped sites) and consisted of 19 Ciona sequences (see Supplementary Table S4). C. savignyi Herdman, 1882 sensu Roule, 1884 was not included in the $\mathrm{x} 3 \mathrm{n} 1$ alignment since in this species the nad 1 gene is not adjacent to $\operatorname{cox} 3-\operatorname{tnK}$.

Phylogenetic reconstructions were performed with the Maximum Likelihood (ML) method and by Bayesian Inference (BI). For ML, we used the online PhyML-SMS v3.0 software, which includes the automatic model selection by Smart Model Selection (SMS) (Guindon \& Gascuel, 2003; Lefort et al., 2017) (http://www.atgc-montpellier.fr/phyml-sms/). The best-fit substitution model selected under the Akaike Information Criterion (AIC) was the GTR $+\mathrm{I}+\mathrm{G}$ for both the $\operatorname{cox} 1$ and the $\mathrm{x} 2 \mathrm{cb}$ alignments, and the $\mathrm{TN} 93+\mathrm{G}$ for the $\mathrm{x} 3 \mathrm{n} 1$ alignment. The proportion of invariant sites (I) and the gamma shape parameter (alpha) for the 4 rate categories were estimated by the PhyML v3.0 software itself. Bootstrap values, indicating node reliability, were based on 100 replicates. Bayesian trees were inferred with MrBayes v. 3.2.7a (Ronquist et al., 2012). The BI analyses were performed using the model already selected by PhyML-SMS. However, the more general GTR $+\mathrm{G}$ model was used for the $\mathrm{x} 3 \mathrm{n} 1$ alignment instead of the TN93+G, since this last model is not implemented in MrBayes. Two parallel analyses, each composed of one cold and three incrementally heated chains, were run for 
$1,000,000$ generations. Trees were sampled every 100 generations and the results of the initial 250,000 generations were discarded (burn-in fraction of $25 \%$ ), after verifying that stationarity of the $\operatorname{lnL}$ was reached. The PSRF (Potential Scale Reduction Factor) was also checked as convergent diagnostic, according to the indications reported in the MrBayes manual. Therefore, a total of 7,500 tree were used to calculate the Bayesian posterior probabilities (BPP) at the different nodes.

Species delimitation analyses were carried out with two methods based on completely different approaches: the Automatic Barcode Gap Discovery method (ABGD; Puillandre et al., 2012), a sequence similarity clustering method, and the Poisson Tree Processes (PTP; Zhang et al., 2013), a tree-based coalescence method. ABGD clusters sequences into partitions, consisting of hypothetical species, based on the statistical inference of the "barcode gap", i.e., the gap in the distribution of intraspecies and inter-species pairwise distances. On the contrary, PTP infers putative species boundaries on a non-ultrametric input tree assuming the existence of two independent classes of Poisson processes, one describing speciation and the other coalescent events. The hypothetical species identified by the two methods are hereafter referred as Operational Taxonomic Units (OTUs). These methods were applied only to the $\operatorname{cox} 1$ and the $\mathrm{x} 3 \mathrm{n} 1$ datasets, since they consist of at least three sequences per most species, a number suitable for the species delimitation analyses.

ABGD analyses were performed on the web-based interface http://wwwabi.snv.jussieu.fr/public/abgd/ (Puillandre et al., 2012), initially using the default values for both the proxy of the minimum relative gap width $(\mathrm{X}=1.5)$ and the scanned range of prior intraspecific divergence (Pmin - Pmax: $0.001-0.1$ ). Then, the robustness of the ABGD results was checked by changing the parameter value one at a time, in particular by increasing Pmax (to 0.2 or 0.3) in order to take into account the fast substitution rate typical of ascidians (Yokobori et al., 1999; Tsagkogeorga et al., 2010; Rubinstein et al., 2013), and by decreasing/increasing X (to 1, 2, 3) in order to verify the existence/avoid smaller local gaps. For each $\mathrm{X}$ and Pmax value, the pairwise distances were calculated according to the three nucleotide substitution models available in ABGD: Jukes-Cantor (JC) (Jukes \& Cantor, 1969), Kimura 2 parameter (K2P) (Kimura, 1980) and uncorrected p-distances ( $\mathrm{p}$-dist). This strategy allowed excluding possible bias of the selected evolutionary model on the OTU delimitation. Therefore, a total of 18 ABGD analyses were performed per alignment.

Since our cox1 alignment contains several missing data, i.e., gapped sites related to the different length of the sequences available in $\mathrm{nr}-\mathrm{nt} \mathrm{db}$ (see Supplementary Table S2), to exclude potential bias due to these sites, the ABGD analyses were carried out on the following four cox1 alignments (without outgroup), consisting of:

- all the 1566 (gapped plus ungapped) sites of all 54 Ciona sequences (1566-All);

- the only 451 ungapped sites present in all 54 Ciona sequences (451-Nogap-All);

- 737 ungapped sites obtained after excluding the 7 shortest Ciona sequences (737-Nogap47taxa) (see Supplementary Table S2 for the excluded taxa);

- 1084 sites, with only six gapped sites, obtained considering only the 12 longest Ciona sequences (1084-12taxa). Thus, this alignment includes only 1 or 2 sequences per species (see Supplementary Table S2 for the included taxa).

The $\mathrm{x} 3 \mathrm{n} 1$ alignment was analysed as it is, including gapped sites, since in this case the gapped sites correspond to real insertion/deletions, not to missing data.

The PTP method (Zhang et al., 2013) was applied to the cox1 and $\mathrm{x} 3 \mathrm{n} 1$ datasets using as input both the ML and the Bayesian tree, although PTP was demonstrated to be quite robust to different tree reconstruction methods (Tang et al., 2014) The Bayesian implementation of the PTP (bPTP) was 
performed through the web interface http://species.h-its.org/ptp/ (Zhang et al., 2013) removing the outgroup and using the following parameters: 500,000 MCMC generations, thinning every 100 generations and a burn-in fraction of 0.20 . The convergence of the MCMC chains was confirmed by visual inspection of the likelihood plot, as reported in the PTP help (https://species.h-its.org/help/), and the maximum likelihood solution was recorded.

\section{Results}

Based on our integrative taxonomy approach, we can confidently hypothesize that the collected specimens belong to a new species, Ciona intermedia. As detailed below, in our approach we considered numerous morphological characters, some ecological characteristics, and three molecular markers: two mitochondrial regions (COI-1.2kb and $\mathrm{x} 3 \mathrm{n} 1$ ) already successfully used for discriminating cryptic species within the so-called Ciona intestinalis species complex (Nydam \& Harrison, 2007; Iannelli et al., 2007; Zhan et al., 2010), and the new fragment x2cb, here examined for the first time for reconstructing the phylogeny of the genus Ciona.

FAMILY CIONIDAE LAHILLE, 1887

GENUS CIONA FLEMING, 1822

CIONA INTERMEDIA NOV. SP. MASTROTOTARO

\section{Etymology}

The specific name refers to some anatomical features of this species which appear intermediate (intermedius, in latin) compared to the already known species belonging to the genus Ciona.

\section{Type material}

Holotype: MUZAC-6550, $7 \mathrm{~cm}$ in height, July 2014, collected by Mastrototaro F. and Chimienti G., type locality, 3-5 m depth, dissected, preserved in 4\% formalin.

Paratypes: MUZAC-6551 and MUZAC-6552, two specimens preserved in 99\% ethanol, collected by Mastrototaro F. and Chimienti G., type locality, 3-5 m depth, not dissected. The holotype and the paratypes have been deposited in the collection of the Zoological Museum of the University of Bari.

\section{Type locality}

Olbia, North-eastern coasts of Sardinia, Italy (4054'55'’N; 9³4'05'’E).

\section{Morphological description}

Smooth and soft tunic, semi-transparent without tubercular prominences. The inner part of the animal is visible and characterized by a reddish anterior region. The red pigmentation is due to the red-orange spots present in the anterior part of the body wall, that becomes red intense near the siphons (Fig. 1AC; Fig. 2A-C). In living specimens, the tunic does not follow the body during sudden contractions (Fig. 1A, 1C).

The oral and the atrial siphons have almost the same length (Fig. 2A-B), with the oral one slightly longer. The oral aperture has 8 lobes while the atrial has 6 lobes (Fig. 2E). One red-orange ocellus lies between each lobe (Fig. 2F). At the base of the oral siphon there are about 30 narrow tentacles of different length, the longest alternating with the shortest ones (Fig. 3A-B). 
The ripe specimen sampled is about $7 \mathrm{~cm}$ in length with the tunic, $5 \mathrm{~cm}$ extracted from the tunic (Fig. 2A-C). Thoracic wall is characterized by a strong musculature that consists of a longitudinal system of six well-defined bands of muscles running from the basal attachment to the siphons (Fig. 2C-E; Fig. 5B), while the circular system is composed by thin transverse strands, encircling the whole body and very evident on both siphons (Fig. 2G).

On each side, the oral siphon is crossed by 4 bands of longitudinal muscles that reach the margin of the oral lobes, while the atrial siphon is supplied by the other two longitudinal bands (Fig. 2E).

The prepharyngeal area (Fig. 3A) does not have papillae (Fig. 3B). The flat pharynx (Fig. 3H) occupies a wide part of the zooid, consisting of many longitudinal vessels and numerous stigmata (Fig. 3F). The stigmata are crossed by narrow parastigmatic vessels (Fig. 3F). At each intersection between transverse vessels and longitudinal vessels, is placed a ventrally-notched papilla (Fig. 3G). In the observed specimens the number of longitudinal vessels on each side of the pharynx is 36 , and the stigmata per mesh in the middle portion of the animal is four (Fig. 3E); these characters are considered not fixed but variable with the size of the specimens in the other known Ciona species (Millar, 1953; Kott, 1990). No significant difference is noted in the meshes of the anterior and posterior part of the pharynx. The dorsal lamina is divided in numerous languets corresponding to the transverse vessels (Fig. 3D) with the endostylar appendix placed at its end (Fig. 3C).

The digestive system occupies about $1 / 4$ of the whole size of the zooid, at its posterior end (Fig. 4A). The wide stomach is ovoid in shape and lies on the left side of the zooid. In particular, it is positioned slightly to the right of the middle line, beneath the pharynx. In living specimens, the alimentary canal is clearly visible, with the orange stomach having about 40 irregular broken folds on its surface (Fig. 4A-B). The intestine ends with a lobed anus that opens at the level of $1 / 3$ of the upper part of the pharynx (Fig. 4A). The rectum is less long than the gonoducts (Fig. 4C).

The ovary, containing a large number of brown-yellowish oocytes of about $100 \mu \mathrm{m}$ in diameter (Fig. 4C-D; Fig. 6A 1 ), is positioned in the inner part of the sinusoidal loop formed by the gut. The oviduct extends parallel to the rectum, projecting beyond the anus with the spermiduct running laterally to it (Fig. 4C). The walls and the end of the gonoducts are yellow-orange. The spermiduct is visible by the accumulation of white sperm (Fig. 4C) with four to eight white narrow papillae projecting from its distal end (four visible papillae in Fig. 4E and Fig. 6A). The branching system of tubular follicles forming the testis lays on both stomach and intestine, forming two major ducts which are joined at the level of the ovary (Fig. 4F); this single spermiduct runs parallel to the oviduct up to the genital aperture (Fig. 4C).

\section{Molecular phylogenetic reconstructions}

The identity percentage between $C$. intermedia and other Ciona species, including C. roulei and C. edwardsi, is lower than $94.28 \%$ for $\operatorname{cox} 1,90.14 \%$ for $\mathrm{x} 3 \mathrm{n} 1$, and $91.89 \%$ for $\mathrm{x} 2 \mathrm{cb}$. The cox 1 value is very distant from the $2-3 \%$ divergence found in several taxonomic groups as maximum cox 1 intraspecific divergence (Hebert et al., 2003; Hebert et al., 2004; Smith et al., 2005), thus providing a first clue that $C$. intermedia could not belong to any already molecularly characterized Ciona species (i.e., C. intestinalis sensu Brunetti et al., 2015, C. robusta, C. savignyi, C. roulei, C. edwardsi, Ciona spC and $\mathrm{spD})$.

Figure 7 summarizes the results of the species delimitation analyses and the phylogenetic reconstructions carried out on cox1. The bPTP method consistently identifies C. intermedia as a distinct OTU, using both the Bayesian and the ML tree as input (see bPTP-Btree and bPTP-MLtree bars, respectively, in Fig. 7). The other recognized OTUs correspond to already described species ( $C$. 
edwardsi, C. robusta an C. savignyi), to a species so far defined only molecularly (Ciona spD), and to the cluster including both C. intestinalis and C. roulei (Fig. 7). Unlike what is expected, Ciona spC is not recognized as a single OTU but as 2-3 OTUs depending on the input tree (see differences between bPTP-Btree and bPTP-MLtree bars in Fig.7). The ABGD results demonstrate the existence of the barcode gap and show a perfect match between the initial and the recursive partitions for prior intraspecific divergences ranging from $0.1-0.28 \%$ (depending on the used alignment and parameter options) to $5.99 \%$ (see Supplementary Table S5). The results of the 72 (i.e., 18x4) ABGD analyses confirm the OTUs identified by bPTP, except for Ciona spC and few sporadic inconsistencies (Fig. 7 and Supplementary Table S5). Indeed, Ciona $\mathrm{spC}$ is recognized as a single OTU in all ABGD analyses, except for few partitions obtained with $\mathrm{X}=1$, where even other species are incongruously split in several improbable OTUs (see red values in square brackets in Supplementary Table S5). Ciona intermedia is recognized as a single OTU in all ABGD analyses except in one case. Indeed, it is merged with $\mathrm{C}$. edwardsi into a single OTU only in the initial and recursive partitions corresponding to a prior intraspecific divergence of $2.15 \%$, obtained in the ABGD performed on the 1566-All alignment using the p-dist (see Supplementary table S5). Going into details of the 72 ABGD results (Supplementary Table S5), the 18 analyses performed on the same alignment with different parameters/substitution models give identical results, with only few exceptions mainly when using the p-dist (see 1566-All and 737-Nogap-47taxa alignments) or at the lowest prior intraspecific divergences for $\mathrm{X}=1$ especially in the alignment with the lowest site number (see square brackets values for the 451-Nogap-All alignment in Supplementary Table S5). Even the results of the ABGD analyses performed on the four different cox1 alignments (i.e., 1566-All, 451-Nogap-All, 737-Nogap47taxa and 1084-12taxa) are almost identical, since they identify OTUs with the same composition, except for some recursive partitions at the lowest prior intraspecific divergences for $X=1$ (see square brackets values in Supplementary Table S5). Remarkably, the 737-Nogap-47taxa and 1084-12taxa alignments give almost identical results in spite of the very different species representativeness $(\geq 3$ sequences per most species in the 737-Nogap-47taxa alignment; only 1-2 sequences per species in the 1084-12taxa alignment). All these results indicate that, at least for our cox 1 dataset, the ABGD method is quite robust to parameter variation, presence of missing data, and differences in species representativeness, thus making us quite confident on the obtained results.

Remarkably, the OTUs identified by the bPTP and ABGD analyses on cox1 correspond to clades strongly supported in the cox1 phylogenetic trees (Fig. 7). Indeed, the bPTP/ABGD OTUs consisting of more than one specimen form statistically significant clades that have both ML bootstrap support $\geq 90 \%$ and BPP $\geq 0.99$ (black dots in Fig. 7). Even the OTU mixing C. roulei and C. intestinalis sequences is identified as a well-supported clade (ML bootstrap: 95\% and BPP: 1). Noteworthy, $C$. intermedia forms the sister group of C. edwardsi, and this relationship is again strongly supported (ML bootstrap: 99\% and BPP: 1) (Fig. 7). Unfortunately, the basal nodes of Figure 7 remain unresolved. Therefore, our COI-1.2kb fragment is able to discriminate different Ciona species, demonstrating to be a robust DNA barcode for the Ciona genus, but it is unable to clarify the exact phylogenetic relationships among the species.

The species delimitation analyses and the ML/Bayesian phylogenetic reconstructions based on the x3n1 fragment (Fig. 8) confirms the results obtained with cox1 (Fig. 7). Indeed, the bPTPs based on both the ML and the Bayesian trees give identical results and discriminate six OTUs, corresponding to: C. intermedia; two already described species (C. edwardsi and C. robusta); two molecularlyidentified cryptic species ( $\mathrm{spC}$ and $\mathrm{spD}$ ); and a clade consisting of $C$. intestinalis plus C. roulei (Fig. 8). The ABGD analyses indicate the existence of a clear barcode gap and show a perfect match 
between initial and recursive partitions at prior intraspecific divergences ranging from $0.77-1.29 \%$ (depending on distance metric) to 5.99\% (see Supplementary Table S5). The results of the 18 ABGD analyses performed with different parameters/substitution models are mainly congruent (Supplementary Table S5) and identical to bPTP (Fig. 8). Few differences are observed only in the recursive partitions at the lowest intraspecies divergence (where C. roulei is recognized as a distinct OTU; see dashed bars in Fig. 8), and at prior intraspecific divergence of $0.77 \%-1.29 \%$ when using the p-dist (where $C$. intermedia is clustered with $C$. edwardsi in the same OTU) (see red values in Supplementary Table S5). The $\mathrm{x} 3 \mathrm{n} 1$ phylogenetic reconstructions recognize as highly supported: the sister relationship between C. intermedia and C. edwardsi (maximum bootstrap and BPP values); two clades corresponding to single species (i.e., Ciona $\mathrm{spD}$, C. robusta); the clustering of C. intestinalis with $C$. roulei (see black dots in Fig. 8). The sister relationship of $\mathrm{spC}$ to the $C$. intermedia-C. edwardsi clade obtains only marginal support (ML bootstrap: 57\%; BPP: 0.91), so it needs to be confirmed by additional data. As cox1, even $\mathrm{x} 3 \mathrm{n} 1$ leaves unresolved the basal nodes of the Ciona tree. Figure 8 reports also the internal structure of the $\mathrm{x} 3 \mathrm{n} 1$ mitochondrial fragment, highlighting that the gene order cox3-trnK-nad1 is conserved in all reported Ciona species (except for C. savignyi, see Materials and Methods). On the contrary, the length of the non-coding spacers upstream and downstream trnK varies between species (see yellow and blue boxes in Fig. 8), thus causing the overall size variability of the $\mathrm{x} 3 \mathrm{n} 1$ fragment between species.

The $\mathrm{x} 2 \mathrm{cb}$ fragment is about $1.1 \mathrm{~kb}$ long and is characterized by a short overlap between the ORFs (Open Reading Frame) of the two genes in all three species C. intermedia, C. edwardsi and C. roulei here analysed for the first time. The same situation was found in all other published $\mathrm{mt}$ genomes of Ciona species (see Supplementary Table S3). The ML and Bayesian phylogenetic reconstructions based on this $\mathrm{x} 2 \mathrm{cb}$ fragment are shown in Figure 9. Remarkably, all nodes of this phylogeny, including the basal ones, are fully resolved (ML bootstrap $\geq 93 \%$ and BPP $\geq 0.97$; see black dots in Fig. 9), thus providing clear information about the relationships between the Ciona species: $C$. intermedia is confirmed as the sister clade of C. edwardsi, while C. robusta is the sister group of the cluster mixing C. intestinalis and C. roulei. Finally, C. savignyi is basal to the remaining Ciona species.

\section{Discussion}

The family Cionidae Lahille, 1887 includes the three genera Ciona, Araneum and Tantillulum, characterized by solitary animals with a transparent tunic, stomach positioned under the pharynx and gonad lying in the gut loop (Brunetti \& Mastrototaro, 2017). The genus Ciona is typical of shallow waters but also includes some abyssal species (Brunetti \& Mastrototaro, 2017) and even C. intestinalis has been found below $100 \mathrm{~m}$ deep in Oslo fjord (Dybern, 1967). This genus can be distinguished for the presence of longitudinal and parastigmatic vessels with papillae in the pharynx; oral and atrial siphons with 8-10 and 6-8 lobes, respectively; and the presence of ocelli between the lobes. In some species the endostyle ends with an appendix, while the stomach lies on the left side of the zooid (Millar, 1953; Brunetti \& Mastrototaro, 2017). Some characteristics of the papillae projecting from the spermiduct (i.e., shape, number and pigmentation) and the oocyte size have been used as further features to allow specific identification. In particular, these characters have been previously described in four Ciona species (Hoshino \& Nishikawa, 1985; Caputi et al., 2007; Sato et al., 2012; Supplementary Material in Malfant et al., 2018) (Fig. 6). 
The morphological and ecological traits of the specimens described in this study confirm their belonging to the Ciona genus but do not fit into any of the already described Ciona species reported so far in the Mediterranean as well as in other seas. In the genus Ciona, fourteen species are currently valid and here briefly described: C. antarctica Hartmeyer, 1911, C. edwardsi, C. fascicularis Hancock, 1870, C. gelatinosa Bonnevie, 1896, C. hoshinoi Monniot, 1991, C. imperfecta Monniot \& Monniot, 1977, C. intestinalis, C. longissima Hartmeyer, 1899, C. mollis Ritter, 1907, C. pomponiae Monniot \& Monniot, 1989, C. robusta, C. roulei, C. savignyi, and C. sheikoi Sananmyan, 1998.

Ciona antarctica was rarely collected and only in Antarctic waters from 300 to $500 \mathrm{~m}$ of depth (Hartmeyer, 1911; Monniot \& Monniot, 1983; Ramos-Esplá et al., 2005; Monniot et al., 2011). This species is characterized by a peculiar organ on each side of the posterior part of the body, between the gut and the body wall, made of thick lobed lamellae of unknown function and by the gonoducts ending before the anus (Monniot, 1998). Also C. gelatinosa, species collected in the Arctic, North Atlantic (Van Name, 1945; Hoshino \& Nishikawa, 1985) and North-eastern Pacific (Sanamyan \& Sanamyan, 2007), is characterized by the gonoducts ending before the anus, as well as by a large muscular post-abdominal extension of the body wall, no endostylar appendix, and the absence of pigment spots around male papillae or on other parts of the body (Sanamyan \& Sanamyan, 2007). Ciona fascicularis has been recorded mainly along the North-western Atlantic coasts and presents peculiar cylindrical rhizoids at the base of the body (Hancock, 1870; Monniot, 1963). Ciona hoshinoi is known from a single specimen from New Caledonia and another one collected in Palau, both of $1.5 \mathrm{~cm}$ in length, with the Palau specimen extremely contracted (Monniot, 1991; Monniot \& Monniot, 2001). This species is mainly characterized by the presence of small round papillae between transverse vessels and longitudinal vessels and smaller papillae associated only to the parastigmatic vessels, as well as a smooth stomach, and anus ending at the level of the gonoducts aperture (Monniot, 1991). Ciona imperfecta is an abyssal species recorded at $4000 \mathrm{~m}$ depth. It lacks the endostylar appendix and has a pharynx consisting of only 4 rows of stigmata and 5-6 longitudinal vessels (Brunetti \& Mastrototaro, 2017). Ciona longissima has a peculiar long stalk at the base of its body and has been recorded only in Arctic waters deeper than $1000 \mathrm{~m}$. Ciona mollis was collected for the first time by Ritter in 1907 off California at $2000 \mathrm{~m}$ depth, and subsequently in the Mexican Pacific at $4400 \mathrm{~m}$ depth (Monniot, 1998). The musculature of this species is peculiar: six strong muscular bands on each side converge to a round area along the ventral side, with the bands stopping at the end of this area. Moreover, C. mollis has a bilobed anus ending near the gonoducts aperture, the spermiduct characterized by only one papilla, no endostylar appendix and no transverse body muscles. Ciona pomponiae was originally described on only one specimen collected between 300 and $800 \mathrm{~m}$ of depth off the Galapagos Islands (Monniot \& Monniot, 1989), and subsequently it was recorded in the North-eastern Pacific (Sanamyan \& Sanamyan, 2007) and from the Bering Sea as Ciona gefesti Sanamyan, 1998 (Sanamyan, 1998) (synonymized by Sanamyan \& Sanamyan in 2007 with C. pomponiae). Ciona pomponiae has only four longitudinal muscles bands, and a stomach with folds not well defined and not clearly distinct from the intestine (Sanamyan \& Sanamyan, 2007). Finally, the description of the species C. sheikoi is based on twelve specimens recorded in the Northwestern Pacific region, all characterized by thick longitudinal mantle muscles, long and remarkably curved gonads and well-defined cylindrical lobes around the anus. Moreover, this species presents papillae on the enlarged posterior part of the tunic, no endostylar appendix, and a smooth stomach with the anus placed near the gonoducts openings (Sanamyan, 1998). Each of the above-described species has peculiarities preventing their possible mis-identification with $C$. intermedia. The remaining five species are currently known in the Mediterranean Sea. In particular, C. intestinalis and 
C. robusta are both characterized by a pleated branchial wall (like an accordion), 5-6 longitudinal muscles (usually 5 with the third divided in two bands) and transverse vessels of different sizes. Moreover, C. robusta can be distinguished from the very similar congeneric $C$. intestinalis also by the presence of several tubercles on the surface of the tunic, especially around the siphons, where they are usually arranged in longitudinal rows (Brunetti et al., 2015). Ciona edwardsi is typically found in shady sites and in circalittoral-moderate deep waters and has a bright sulphur-yellow coloration (Fig.1D-E) (Mastrototato \& Relini, 2011). At morphological level, this species is characterized by 6 longitudinal muscles bands (Fig. 5C), and by a pharynx with a flat branchial wall and transverse vessels of about equal sizes (Copello et al., 1981; Mastrototaro et al., 2000; Mastrototaro \& Relini, 2011; Brunetti \& Mastrototaro, 2017). Ciona roulei, a poorly described species, is mainly characterized by the presence of four longitudinal muscle bands (with the third divided in two bands) and a reddish coloration (Lahille, 1890; Harant \& Vernièries, 1933; Brunetti $\&$ Mastrototaro, 2017). Moreover, the validity of this last species is yet questionable, as suggested by the results of crossing experiments (Malfant et al., 2018), as well as by molecular phylogenetic reconstructions within the Ciona genus based on both nuclear and mitochondrial genes (Nydam \& Harrison, 2007, 2010; See tree in Figure S1 in Malfant et al., 2018). Finally, C. savignyi, firstly collected and described by Herdman (1882), is characterized by a whitish-grey tunic, large paddleshaped papillae on the intersection between transverse and longitudinal vessels and no endostylar appendix (Hoshino \& Nishikawa, 1985; Brunetti \& Mastrototaro, 2017). However, the presence of this species in the Mediterranean Sea is doubtful (Brunetti \& Mastrototaro, 2017).

As summarized in Table 2, C. intermedia sp. nov. shows intermediate characters between those of the above reported Ciona species, i.e., a mixture of features, each one in common with only one/some of the other shallow-water Ciona species. In particular, C. intermedia has been found in shady sites as has C. edwardsi (Table 2); it has six longitudinal muscles bands like all other species except for $C$. roulei (Fig. 5); a flat pharynx as in C. edwardsi, instead of the accordion-shaped of C. intestinalis and C. robusta (Fig. $3 \mathrm{H}$ ); transverse vessels of about equal sizes, as in C. edwardsi and C. roulei (Brunetti $\&$ Mastrototaro, 2017); a smooth tunic surface without the tubercles identified as diagnostic feature of C. robusta by Brunetti et al., 2015 (Table 2). Ciona intermedia appears morphologically very similar to C. edwardsi (Table 2), but it has been found in shallower location (i.e., littoral-shallow, at 3-5 m depth, whereas C. edwardsi is commonly present in circalittoral-moderate deep waters, at 20$40 \mathrm{~m}$ depth) and displays a different pigmentation. Although the coloration is generally not considered as a valid taxonomic character, it is important to point out that all C. edwardsi records showed a characteristic sulphur-yellow coloration (Copello et al., 1981; Mastrototaro et al., 2000; Mastrototaro \& Relini, 2011) (Table 2). Concerning the number of papillae projecting from the spermiduct, the specimens of $C$. intermedia show from 4 to 8 narrow uncoloured papillae at the distal end of the spermiduct (Fig. 6A), a situation more similar to that of C. intestinalis (Fig. 6C), while C. edwardsi shows a turf of 15-30 thick white papillae projecting from all around the spermiduct, as reported by Hoshino \& Nishikawa (1985) (Fig. 6B) (see also Table 2). Ciona robusta is characterized by ellipsoidal papillae usually orange-coloured, although their colour cannot be considered a true diagnostic character (Fig. 6G) (see also as C. intestinalis sp.A in Caputi et al., 2007 and Sato et al., 2012; Brunetti et al., 2015; Malfant et al., 2018). Finally, as for the oocytes size, the C. edwardsi oocyte diameter is almost twice that of the other three analysed species and they present a narrower follicular envelope (Fig. 6A $1, \mathrm{~B}_{1}, \mathrm{C}_{1}, \mathrm{D}_{1}$ ). A larger size of the $C$. edwardsi oocytes has been also reported by Malfant et al., (2018) in comparison with C. robusta, C. intestinalis and C. roulei. 
The examination of a larger number of $C$. intermedia specimens is needed for further verifying the intra-species variability of the morphological traits here investigated, as well as for searching character(s) unique of this species, if any.

As for the molecular data, the species delimitation analyses have been carried out with a clustering (ABGD) and a tree-based (bPTP) method on two molecular markers: COI-1.2kb (i.e., an elongation of the classical cox1 DNA barcode), and $\mathrm{x} 3 \mathrm{n} 1$. Both methods and markers consistently recognize $C$. intermedia as a distinct OTU and confirm that it cannot be assigned to any known described or undescribed Ciona species, including Ciona spC and spD currently defined only molecularly (Fig. 78). The congruency of these results increases the confidence in their validity. Indeed, the combined usage of two distinct methods/markers allows compensating for possible confounding factors differentially affecting the efficacy and/or sensitivity of each method/marker. As for the sample size and species representativeness, our datasets consist of at least three sequences per $50-70 \%$ of the expected species (for the $\mathrm{x} 3 \mathrm{n} 1$ and cox 1 alignments, respectively), thus it is characterized by an uneven sampling similar to that observed in other species delimitation studies (see for example Kekkonen \& Hebert, 2014; Kekkonen et al., 2015). Based on simulation tests (Puillandre N., personal communication) and on the many papers that have used ABGD in combination with other methods, ABGD works well enough even when some species in the dataset include only 1-2 specimens (Ahrens et al., 2016; Kekkonen \& Herbert, 2014; Kekkonen et al., 2015). Moreover, in our case, the unbalanced sampling is due to the fact that not only $C$. intermedia but also spC and spD have been found and sampled in only one locality (Nydam \& Harrison 2007, 2010; Zhan et al., 2010). Therefore, these three species belong to the called "singletons", estimated to account for about $30 \%$ of the formally described invertebrate species (Lim et al., 2012). The commonness of rarity in nature and the consequent incomplete taxon sampling is a problem common to many DNA-based species delimitation studies (Lim et al., 2012). However, recent analyses have shown that the shortcomings of poor and unbalanced sampling can be overcome including data from related lineages (the so called "subclade addition"), i.e., by extending the study of a focal clade to a broader set of species (Talavera et al., 2013; Ahrens et al., 2016). Ahrens et al., (2016) have also shown that this strategy has a different performance on the different species delimitation methods. In particular, in subclade analyses ABGD decreases, while PTP increases the number of recognized OTUs compared to the analysis of a total dataset consisting of all subclades, with consequent variation of the match to morpho-species (Ahrens et al., 2016). Here, in order to at least mitigate the singleton issue in our datasets, we have analysed the sequences of all available Ciona species with the two methods, ABGD and PTP, that were shown to be differently affected by the uneven sampling and to have a different response to the subclade addition strategy (Ahrens et al., 2016). Nevertheless, both ABGD and PTP methods gave consistent results, including the identification of $C$. intermedia as a distinct species.

Ciona intermedia is identified as the sister group of C. edwardsi with high statistical support in all ML and Bayesian phylogenetic reconstructions based on all three analysed mt fragments (Fig. 7-9), thus corroborating the close similarity already observed at morphological level. Interestingly, interspecific crosses between C. edwardsi and any of the three species C. intestinalis, C. robusta and C. roulei revealed strong reproductive isolation (Lambert et al., 1990; Malfant et al., 2018). Therefore, given the strong genetic similarity between $C$. intermedia and C. edwardsi, we can hypothesize that C. intermedia might also be reproductively isolated from other Ciona species. Of course, this hypothesis needs to be experimentally tested. The use of nuclear markers could also be helpful to better delineate these two species and investigate their past demographic history, as it was done for C. intestinalis and C. robusta (Roux et al., 2013; Bouchemousse et al., 2016b). 
Finally, the phylogeny of the genus Ciona inferred from x $2 \mathrm{cb}$ gives for the first time a well-resolved picture of the relationships within this genus, even at basal level (Fig. 9). Indeed, the basal nodes of the Ciona tree are unresolved in all previously published phylogenetic reconstructions of this genus, that were based on a cox1 fragment of only 750-bp (Nydam \& Harrison, 2007; Malfant et al., 2018), on nuclear genes (Nydam \& Harrison, 2010) or on combined nuclear and mt sequences (Zhan et al., 2010). Noteworthy, even these previous phylogenetic reconstructions do not include one or two of the following rarely molecularly sampled Ciona species: spC, spD and C. edwardsi species (lack of spD in Nydam \& Harrison, 2007, 2010; lack of C. edwardsi in Zhan et al., 2010; lack of spC and spD in Malfant et al., 2018), so they analyse an incomplete species dataset exactly as our x2cb tree. Therefore, the better resolution observed in our $\mathrm{x} 2 \mathrm{cb}$ phylogenetic tree cannot be an artefact related to the analysis of a reduced taxon sampling (i.e., lack of $\mathrm{spC}$ and $\mathrm{spD}$ ). Furthermore, our results show that $\mathrm{x} 2 \mathrm{cb}$ has a resolving power even higher than the cox 1 fragment of about $1.2 \mathrm{~kb}$, since it is able to resolve all nodes that instead remain unresolved in our COI-1.2kb tree (compare Fig. 9 to Fig. 7). Moreover, even the COI-1.2kb ML and Bayesian trees reconstructed using exactly the same taxon sampling of $\mathrm{x} 2 \mathrm{cb}$ (i.e., excluding $\mathrm{spC}$ and $\mathrm{spD}$ from the cox1 dataset) are not fully resolved (data not shown), supporting the conclusion that the low resolution of $\operatorname{cox} 1$ is not related to the presence of spC and $\mathrm{spD}$. Thus, although the $\mathrm{x} 2 \mathrm{cb}$ sequences of $\mathrm{spC}$ and $\mathrm{spD}$ are essential to further confirm our observations, we strongly encourage using the $\mathrm{x} 2 \mathrm{cb}$ fragment as a new molecular marker in future analyses on the Ciona species.

In conclusion, our results point to an integrative taxonomy approach, involving the analysis of morphological, ecological and molecular characters, as a fundamental requirement for the delineation and the description of new Ciona species. This is in accordance with previous studies of the Ciona genus, where molecular data were crucial for addressing morphological re-analyses and taxonomic revisions (Suzuki et al., 2005; Caputi et al., 2007; Iannelli et al., 2007; Nydam \& Harrison, 2007, 2010; Zhan et al., 2010; Sato et al., 2012; Brunetti et al., 2015; Pennati et al., 2015; Gissi et al., 2017; Malfant et al., 2018). In view of these results, the "Ciona case" is still far from being resolved.

\section{Acknowledgements}

This work was partially supported by the MIUR, Italy, to C.G., who also acknowledges the support of the Molecular Biodiversity Laboratory of the Italian node of Lifewatch (CNR). F.V. acknowledges support from the ANR project HYSEA (No. ANR-12-BSV7-0011). The authors thank Marie Nydam for helpful discussion and photographic material; Maarten Christenhusz, Xavier Turon and an anonymous reviewer for their useful suggestions. The authors declare that they have no conflict of interest. 


\section{References}

Altschul SF, Gish W, Miller W, Myers EW, Lipman DJ. 1990. Basic local alignment search tool. Journal of Molecular Biology 215(3): 403-10.

Ahrens D, Fujisawa T, Krammer HJ, Eberle J, Fabrizi S, Vogler AP. 2016. Rarity and Incomplete Sampling in DNA-Based Species Delimitation. Systematic Biology 65: 478-494.

Berrill NJ. 1950. The Tunicata with an account of the British species. London: Ray Society publications.

Bouchemousse S, Bishop J, Viard F. 2016a. Contrasting global genetic patterns in two biologically similar, widespread and invasive Ciona species (Tunicata, Ascidiacea). Scientific Reports 6: 24875.

Bouchemousse S, Liautard-Haag C, Bierne N, Viard F. 2016b. Distinguishing contemporary hybridization from past introgression with postgenomic ancestry-informative SNPs in strongly differentiated Ciona species. Molecular Ecology 25(21): 5527-5542.

Bouchemousse S, Lévêque L, Dubois G, Viard F. 2016c. Co-occurrence and reproductive synchrony do not ensure hybridization between an alien tunicate and its interfertile native congener. Evolutionary Ecology 30: 69-87, doi: 10.1007/s10682-015-9788-1.

Brunetti R, Gissi C, Pennati R, Caicci F, Gasparini F, Manni L. 2015. Morphological evidence that the molecularly determined Ciona intestinalis type A and type B are different species: Ciona robusta and Ciona intestinalis. Journal of Zoological Systematics and Evolutionary Research 53(3): 186-193.

Brunetti R, Manni L, Mastrototaro F, Gissi C, Gasparini F. 2017. Fixation, description and DNA barcode of a neotype for Botryllus schlosseri (Pallas, 1766) (Tunicata, Ascidiacea). Zootaxa 4353: 29-50.

Brunetti R, Mastrototaro F. 2017. Ascidiacea of the European Waters. Milano: Edagricole - New Business Media II.

Caputi L, Andreakis N, Mastrototaro F, Cirino P, Vassillo M, Sordino P. 2007. Cryptic speciation in a model invertebrate chordate. Proceedings of the National Academy of Sciences 104(22): 9364-9369.

Cañestro C, Bassham S, Postlethwait JH. 2003. Seeing chordate evolution through the Ciona genome sequence. Genome Biology 4(3): 208.

Copello M, Devos L, Lafargue F. 1981. Ciona edwardsi (Roule, 1886 [sic]) espèce littorale de Méditerranée distinct de Ciona intestinalis Linné, 1767. Vie Milieu 31: 243-253.

Dehal P, Satou Y, Campbell RK, Chapman J, Degnan B, De Tomaso A, et al. 2002. The draft genome of Ciona intestinalis: insights into chordate and vertebrate origins. Science 298(5601): 21572167.

Dybern BI. 1967. The distribution and salinity tolerance of Ciona intestinalis (L.) F. typica with special reference to the waters around Southern Scandinavia. Ophelia 4(2): 207-226.

Gissi C, Pesole G, Mastrototaro F, Iannelli F, Guida V, Griggio F. 2010. Hypervariability of ascidian mitochondrial gene order: exposing the myth of deuterostome organelle genome stability. Molecular Biology and Evolution 27: 211-215.

Gissi C, Hastings KE, Gasparini F, Stach T, Pennati R, Manni L. 2017. An unprecedented taxonomic revision of a model organism: the paradigmatic case of Ciona robusta and Ciona intestinalis. Zoologica Scripta 46(5): 521-522.

Guindon S, Gascuel O. 2003. A simple, fast, and accurate algorithm to estimate large phylogenies by maximum likelihood. Systematic biology 52(5): 696-704. 
Hancock A. 1870. On the larval state of Molgula; with descriptions of several new species of simple ascidians. Annals of Natural History (4)6: 353-368.

Harant H, Vernières P. 1933. Tuniciers : I Ascidies. Paris : Faune de France 27.

Hartmeyer R. 1909-1911. Ascidien. Dr. HG Bronn's Klassen und Ordnungen des Tier-Reichs, 3(1): 1281-1773.

Hartmeyer R. 1911. Die ascidien der deutschen südpolar expedition 1901-1903. Deutsche SudpolarExpedition 12: 403-606.

Hawkins CJ, Kott P, Parry DL, Swinehart JH. 1983. Vanadium content and oxidation state related to ascidian phylogeny. Comparative Biochemistry and Physiology Part B: Comparative Biochemistry 76(3): 555-558.

Hebert PD, Cywinska A, Ball SL, deWaard JR. 2003. Biological identifications through DNA barcodes. Proceedings of the Royal Society B: Biological Sciences 270: 313-21.

Hebert PDN, Stoeckle MY, Zemlak TS, Francis CM. 2004. Identification of Birds through DNA Barcodes. PLOS Biology 2: e312.

Herdman WA. 1882. Report on the Tunicata collected during the Voyage of HMS Challenger during the years 1873-76. I. Ascidiae simplices. Report of the Scientific Results of the Voyage of HMS Challenger during the Years 1873-76 6: 1-296.

Hirose M, Hirose E, 2009. DNA barcoding in photosymbiotic species of Diplosoma (Ascidiacea: Didemnidae), with the description of a new species from the southern Ryukyus, Japan. Zoological Science 26(8): 564-568.

Hoshino ZI, Tokioka T. 1967. An unusually robust Ciona from the northeastern coast of Honsyu Island, Japan. Publication of the Seto Marine Biological Laboratory 15: 275-290.

Hoshino ZI, Nishikawa T. 1985. Taxonomic studies of Ciona intestinalis (L.) and its allies. Publication of the Seto Marine Biological Laboratory 30(1/3): 61-79.

Iannelli F, Pesole G, Sordino P, Gissi C. 2007 Mitogenomics reveals two cryptic species in Ciona intestinalis. Trends in Genetics 23: 419-422, doi: 10.1016/j.tig.2007.07.001.

ICZN 1999. International Code of Zoological Nomenclature. 4th Edition. London: The International Trust for Zoological Nomenclature, The Natural History Museum.

Jukes TH, Cantor CR. 1969. Evolution of protein molecules. Mammalian protein metabolism 3(24): 22-126.

Katoh K, Misawa K, Kuma KI, Miyata T. 2002. MAFFT: a novel method for rapid multiple sequence alignment based on fast Fourier transform. Nucleic Acids Research 30(14): 3059-3066.

Kearse M, Moir R, Wilson A, Stones-Havas S, Cheung M, Sturrock S, Buxton S, Cooper A, Markowitz S, Duran C, Thierer T, Ashton B, Meintjes P, Drummond A. 2012. Geneious Basic: an integrated and extendable desktop software platform for the organization and analysis of sequence data. Bioinformatics 28(12): 1647-1649.

Kekkonen M, Hebert PDN. 2014. DNA barcode-based delineation of putative species: efficient start for taxonomic workflows. Molecular Ecology Resources 14: 706-715.

Kekkonen M, Mutanen M, Kaila L, Nieminen M, Hebert PDN. 2015. Delineating Species with

DNA Barcodes: A Case of Taxon Dependent Method Performance in Moths. PLOS ONE 10: e0122481.

Kimura M. 1980. A simple method for estimating evolutionary rates of base substitutions through comparative studies of nucleotide sequences. Journal of Molecular Evolution 16(2): 111-120.

Kott P. 1990. The Australian Ascidiacea. Part 2, Aplousobranchia (1). Brisbane: Memoirs of the Queensland Museum. 
Kott P. 2005. Catalogue of Tunicata in Australian Waters. Canberra: Australian Biological Resources Study.

Lahille F. 1887. Faune ascidiologique de Banyuls-sur-Mer. Bulletin de la Société d'histoire naturelle de Toulouse 21: 57-59.

Lahille F. 1890. Recherches sur les Tunicier des côtes de France. Toulouse : Imprimerie Lagarde et Sebille.

Lambert C, Lafargue F, Lambert G. 1990. Preliminary note on the genetic isolation of Ciona species (Ascidiacea, Urochordata). Vie milieu 40: 293-295.

Lefort V, Longueville JE, Gascuel O. 2017. SMS: Smart Model Selection in PhyML. Molecular Biology and Evolution, 34(9):2422-2424.

Lemaire P. 2011. Evolutionary crossroads in developmental biology: the tunicates. Development 138(11): 2143-52, doi: 10.1242/dev.048975

Lim GS, Balke M, Meier R. 2012. Determining Species Boundaries in a World Full of Rarity: Singletons, Species Delimitation Methods. Systematic Biology 61: 165-169.

Malfant M, Darras S, Viard F. 2018. Coupling molecular data and experimental crosses sheds light about species delineation: a case study with the genus Ciona. Scientific Reports 8(1): 1480.

Mastrototaro F, Montesanto F, Salonna M, Grieco F, Trainito E, Chimienti G, Gissi C. 2019. Hitch-hikers of the sea: concurrent morphological and molecular identification of Symplegma brakenhielmi (Tunicata: Ascidiacea) in the western Mediterranean Sea. Mediterranean Marine Science 20(1): 197-207, doi: 10.12681/mms.19390

Mastrototaro F, Tursi A, Costantino G. 2000. Ascidiacei della riserva marina di Ustica. Biologia Marina Mediterranea 7(1): 691-694.

Mastrototaro F, D'onghia G, Tursi A. 2008. Spatial and seasonal distribution of ascidians in a semienclosed basin of the Mediterranean Sea. Journal of the Marine Biological Association of the United Kingdom 88: 1053-1061.

Mastrototaro F, Relini G. 2011. Prima segnalazione di Ciona edwardsi (Roule, 1886) (Tunicata, Ascidiacea) in Mar Ligure. First record of Ciona edwardsi (Roule, 1886) (Tunicata, Ascidiacea) in the Ligurian Sea. Biologia Marina Mediterranea 18(1): 262.

Millar RH. 1953. Ciona. LMBC Memoirs on typical British marine Plants and Animals, 35. Liverpool: Liverpool University press.

Monniot C. 1963. Presence a Bergen de Ciona fascicularis Hancock, 1870. Sarsia 11(1): 5-9.

Monniot C. 1991. Ascidies de Nouvelle-Caledonie. 8. Phlebobraches (suite). Bulletin du Muséum National d'Histoire naturelle 4 (12): 491-515.

Monniot C. 1998. Abyssal ascidians collected from the proximity of hydrothermal vents in the Pacific Ocean. Bulletin of Marine Science 63(3): 541-558.

Monniot F, Dettai A, Eleaume M, Cruaud C, Ameziane N. 2011. Antarctic Ascidians (Tunicata) of the French-Australian survey CEAMARC in Terre Adélie. Zootaxa 2817(1): 1-54.

Monniot C, Monniot F. 1983. Ascidies antarctiques et subantarctiques: morphologie et biogéographie. Mémoires du Museum national d'Histoire naturelle 125: 1-168.

Monniot C, Monniot F. 1989. Ascidians collected around the Galapagos Islands using the JohnsonSea-Link research submersible. Proceedings of the Biological Society of Washington 102(1): 14-32. Monniot F, Monniot C. 2001. Ascidians from the tropical western Pacific. Zoosystema 23(2): 201383.

Nydam ML, Harrison RG. 2007. Genealogical relationships within and among shallow-water Ciona species (Ascidiacea). Marine Biology 151(5): 1839-1847. 
Nydam ML, Harrison RG. 2010. Polymorphism and divergence within the ascidian genus Ciona. Molecular Phylogenetics and Evolution 56(2): 718-726.

Ordóñez V, Pascual M, Fernández-Tejedor M, Turon X. 2016. When invasion biology meets taxonomy: Clavelina oblonga (Ascidiacea) is an old invader in the Mediterranean Sea. Biological Invasions 18: 1203-1215. doi: 10.1007/s10530-016-1062-0

Padial JM, Miralles A, De la Riva I, Vences M. 2010. The integrative future of taxonomy. Frontiers in Zoology 7:16, doi: 10.1186/1742-9994-7-16.

Pennati R, Ficetola GF, Brunetti R, Caicci F, Gasparini F, Griggio F, Sato A, Stach T, Kaul S, Gissi C, Manni L. 2015. Evidence of remarkable morphological differences between larvae of the Ciona intestinalis species complex: hints for a valid taxonomic definition of distinct species. PLoS ONE 10(5):e0122879.

Procaccini G, Affinito O, Toscano F, Sordino P. 2011. A new animal model for merging ecology and evolution. In: Evolutionary Biology - Concepts, Biodiversity, Macroevolution and Genome Evolution 91-106. Berlin: Heidelberg Springer.

Puillandre N, Lambert A, Brouillet S, Achaz G. 2012. ABGD, Automatic Barcode Gap Discovery for primary species delimitation. Molecular Ecology 21(8): 1864-1877.

Ramos-Esplá AA, Cárcel JA, Varela M. 2005. Zoogeographical relationships of the littoral ascidiofauna at the Antarctic Peninsula, in the Scotia Arc and in the Magellan region. Scientia Marina 69(S2): 215-223.

Ronquist F, Teslenko M, Van Der Mark P, Ayres DL, Darling A, Höhna S, Huelsenbeck JP. 2012. MrBayes 3.2: efficient Bayesian phylogenetic inference and model choice across a large model space. Systematic biology, 61(3): 539-542.

Roux C, Tsagkogeorga G, Bierne N, Galtier N. 2013. Crossing the species barrier: genomic hotspots of introgression between two highly divergent Ciona intestinalis species. Molecular Biology and Evolution 30(7): 1574-1587.

Rubinstein ND, Feldstein T, Shenkar N, Botero-Castro F, Griggio F, Mastrototaro F, Delsuc F, Douzery EJ, Gissi C, Huchon D. 2013. Deep sequencing of mixed total DNA without barcodes allows efficient assembly of highly plastic ascidian mitochondrial genomes. Genome Biology and Evolution 5: 1185-99.

Sanamyan K. 1998. Ascidians from the north-western Pacific Region. 5. Phlebobranchia. Ophelia 49(2): 97-116.

Sanamyan K, Sanamyan N. 2007. Poorly known Ascidiacea collected in the vicinity of the Commander Islands and East Kamchatka, NW Pacific. Zootaxa 1579(1): 55-68.

Satoh N, Satou Y, Davidson B, Levine M. 2003. Ciona intestinalis: an emerging model for wholegenome analyses. Trends in Genetics 19(7): 376-381.

Sato A, Satoh N, Bishop JDD. 2012. Field identification of 'types' A and B of the ascidian Ciona intestinalis in a region of sympatry. Marine Biology 159: 1611-1619, doi: 10.1007/s00227-012-18985.

Sato A, Sebastian M. Shimeld SM, Bishop JDD. 2014. Symmetrical reproductive compatibility of two species in the Ciona intestinalis (Ascidiacea) species complex, a model for marine genomics and developmental biology. Zoological Science 31(6): 369-374.

Shenkar N, Koplovitz G, Dray L, Gissi C, Huchon D. 2016. Back to solitude: Solving the phylogenetic position of the Diazonidae using molecular and developmental characters. Molecular Phylogenetics and Evolution 100: 51-56. 
Smith MA, Fisher BL, Hebert PDN. 2005. DNA barcoding for effective biodiversity assessment of a hyperdiverse arthropod group: the ants of Madagascar. Philosophical Transactions of the Royal Society B: Biological Sciences 360: 1825-1834.

Suzuki MM, Nishikawa T, Bird A. 2005. Genomic approaches reveal unexpected genetic divergence within Ciona intestinalis. Journal of Molecular Evolution 61: 627-635

Talavera G, Dincă V, Vila R. 2013. Factors affecting species delimitations with the GMYC model: insights from a butterfly survey. Methods in Ecology and Evolution 4: 1101-1110.

Tang CQ, Humphreys AM, Fontaneto D, Barraclough TG. 2014. Effects of phylogenetic reconstruction method on the robustness of species delimitation using single-locus data (E Paradis, Ed.). Methods in Ecology and Evolution 5: 1086-1094.

Tsagkogeorga G, Turon X, Galtier N, Douzery EJ, Delsuc F. 2010. Accelerated evolutionary rate of housekeeping genes in tunicates. Journal Molecular and Evolution 71: 153-67.

Turon X, López-Legentil S. 2004. Ascidian molecular phylogeny inferred from mtDNA data with emphasis on the Aplousobranchiata. Molecular Phylogenetics and Evolution 33(2): 309-320.

Van Name WG. 1945. The North and South American ascidians. Bulletin of the American Museum of Natural History 84: 1-476.

Yokobori S, Ueda T, Feldmaier-Fuchs G, Pääbo S, Ueshima R, Kondow A, Nishikawa K, Watanabe K. 1999. Complete DNA sequence of the mitochondrial genome of the ascidian Halocynthia roretzi (Chordata, Urochordata). Genetics 153: 1851-1862.

Zhan A, MacIsaac HJ, Cristescu ME. 2010. Invasion genetics of the Ciona intestinalis species complex: from regional endemism to global homogeneity. Molecular Ecology 19(21): 4678-4694.

Zhan A, Briski E, Bock D, Ghabooli S, MacIsaac H. 2015. Ascidians as models for studying invasion success. Marine Biology 162(12): 2449-2470.

Zhang J, Kapli P, Pavlidis P, Stamatakis A. 2013. A general species delimitation method with applications to phylogenetic placements. Bioinformatics 29: 2869-2876. 


\section{Supplementary Tables S1}

Specimens of C. edwardsi, C. intestinalis, and C. robusta of Mastrototaro F. private collection examined in this study. Number of samples, collection site and identifiers are also reported.

\section{Supplementary Tables S2}

List of the aligned cox 1 sequences. Red colour indicates sequences produced in this study. Sequences excluded and included in the alignment "737-Nogap-47taxa" and "1084-12taxa", respectively, are also reported.

\section{Supplementary Tables S3}

List of the cox 2 and $c o b$ sequences included in the alignment of the $\mathrm{x} 2 \mathrm{cb}$ fragment. Red colour indicates sequences produced in this study. ORF: Open Reading Frame

\section{Supplementary Tables S4}

List of the sequences included in the alignment of the $\mathrm{x} 3 \mathrm{n} 1$ fragment. Red colour indicates sequences produced in this study.

\section{Supplementary Tables S5}

Results of the ABGD analyses on the four cox 1 alignments and on the $\mathrm{x} 3 \mathrm{n} 1$ alignment using the default values for parameters $X$ and Pmin-Pmax. The few differences to results obtained with $X=1$, 2 or 3 are also reported within brackets. The $" n^{\circ}$ of expected OTUs" includes one OTU for $C$. intermedia, and one OTU for the clade joining $C$. intestinalis with C. roulei. Red: values different from those expected; round brackets: content of unexpected OTUs merging several species; square brackets: different results obtained with $\mathrm{X}=1$; curly brackets: different results obtained with $\mathrm{X}=2$ and $X=3$; Init: initial partitions; Rec: recursive partitions; nd: not determined. 
Table 1.

Mitochondrial regions and primers used in this study.

\begin{tabular}{|l|l|l|l|l|l|}
\hline $\begin{array}{l}\text { Fragment } \\
\text { name }\end{array}$ & Primer pair & $\mathbf{k b}^{\text {a }}$ & $\begin{array}{l}\text { Primer } \\
\text { name }\end{array}$ & Sequence (5'->3') & Notes/ Reference \\
\hline COI-1.2kb & dinF/ConsR1 & 1.2 & dinF & CGTTGRTTTATRTCTACWAATCATAARGA & Brunetti et al., 2017 \\
\hline & & & consR1 ${ }^{\text {b }}$ & CATTGATYYCCTCTTTTTACTAGATTAAGTTTT & This study \\
\hline x2cb & ux2F/ucbR & 1.1 & ux2F & GYAGTTRGDCAYCARTGATATTG & Iannelli et al., 2007 \\
\hline & & & ucbR & GGAATASAYCGTAAAATVGCATARGC & Iannelli et al., 2007 \\
\hline x3n1 & tx3F/tn1R & $0.6-0.7$ & tx3F & GAGTGTGCKATTTGGTATTGAC & Iannelli et al., 2007 \\
\hline & & & tn1R & ATYTGAGCYACTCCTCGAATTC & Iannelli et al., 2007 \\
\hline
\end{tabular}

a: average range for the known Ciona species

b: consR1 is a modification of the "consensus R" primer of Nydam \& Harrison (2007), obtained by deleting three nucleotides at the 5'end, and the last nucleotide at the 3 ' end, corresponding to a third codon position of cox1. 
Table 2.

Comparison of Ciona intermedia to other four Mediterranean Ciona species.

\begin{tabular}{|c|c|c|c|c|c|}
\hline & C. intestinalis $^{a}$ & C. robusta ${ }^{b}$ & C. roulei & C. edwardsi & C. intermedia \\
\hline Habitat $^{\mathrm{c}}$ & light sites & light sites & - & shady sites & shady sites \\
\hline Colour in vivo & $\begin{array}{c}\text { various: } \\
\text { whitish, reddish } \\
\text { or yellowish }\end{array}$ & $\begin{array}{l}\text { from whitish } \\
\text { to yellowish }\end{array}$ & red & $\begin{array}{l}\text { sulphur- } \\
\text { yellow }\end{array}$ & $\begin{array}{l}\text { Transparent } \\
\text { tunic, siphons } \\
\text { and upper part } \\
\text { of the body } \\
\text { orange-red }\end{array}$ \\
\hline Depth & $\begin{array}{l}\text { littoral, shallow } \\
\text { water }\end{array}$ & $\begin{array}{c}\text { littoral, } \\
\text { shallow water }\end{array}$ & $\begin{array}{c}\text { littoral, } \\
\text { shallow water }\end{array}$ & $\begin{array}{c}\text { circalittoral, } \\
\text { mesophotic } \\
\text { water }\end{array}$ & $\begin{array}{c}\text { littoral, } \\
\text { shallow water }\end{array}$ \\
\hline Size (height) & about $20 \mathrm{~cm}$ & about $20 \mathrm{~cm}$ & about $10 \mathrm{~cm}$ & about $20 \mathrm{~cm}$ & about $7 \mathrm{~cm}$ \\
\hline Test surface & smooth & with tubercles & smooth & smooth & smooth \\
\hline n. of oral lobes & 8 & 8 & - & $8-10$ & 8 \\
\hline $\begin{array}{l}\text { n. of atrial } \\
\text { lobes }\end{array}$ & 6 & 6 & - & $6-8$ & 6 \\
\hline $\begin{array}{l}\text { Muscle bands } \\
{\text { (per side })^{d}}^{\text {per }}\end{array}$ & $5-6$ & $5-6$ & 4 & $5-6$ & 6 \\
\hline Branchial wall & pleated & pleated & - & flat & flat \\
\hline $\begin{array}{l}\text { Transverse } \\
\text { vessels } \\
\text { (observed on } \\
\text { the external } \\
\text { surface) }\end{array}$ & of different size & $\begin{array}{l}\text { of different } \\
\text { size }\end{array}$ & $\begin{array}{c}\text { of about equal } \\
\text { size }\end{array}$ & $\begin{array}{c}\text { of about equal } \\
\text { size }\end{array}$ & $\begin{array}{c}\text { of about equal } \\
\text { size }\end{array}$ \\
\hline $\begin{array}{l}\text { Spermiduct } \\
\text { papillae }\end{array}$ & $\begin{array}{c}5-20, \\
\text { ellipsoidal, } \\
\text { variable in } \\
\text { colour, usually } \\
\text { white }\end{array}$ & $\begin{array}{l}\text { 5-20, thick, } \\
\text { variable in } \\
\text { colour, } \\
\text { usually } \\
\text { orange-red }\end{array}$ & 5-10, white & $\begin{array}{l}\text { 15-30, thick } \\
\text { white-yellow }\end{array}$ & $\begin{array}{l}\text { 4-8, narrow } \\
\text { and white }\end{array}$ \\
\hline $\begin{array}{l}\text { Oocytes } \\
\text { diameter }\end{array}$ & about $100 \mu \mathrm{m}$ & about $100 \mu \mathrm{m}$ & about $100 \mu \mathrm{m}$ & about $200 \mu \mathrm{m}$ & about $100 \mu \mathrm{m}$ \\
\hline
\end{tabular}

a: according to Brunetti et al., (2015), formerly known as C. intestinalis type B

b: according to Brunetti et al., (2015), formerly known as $C$. intestinalis type A

c: differences probably due to the different phototropism of the larvae (positive in C. intestinalis

and C. robusta, probably negative in C. edwardsi) (Brunetti \& Mastrototaro, 2017)

$\mathrm{d}$ : variable character the third band sometimes is divided in two bands 


\section{Figures}

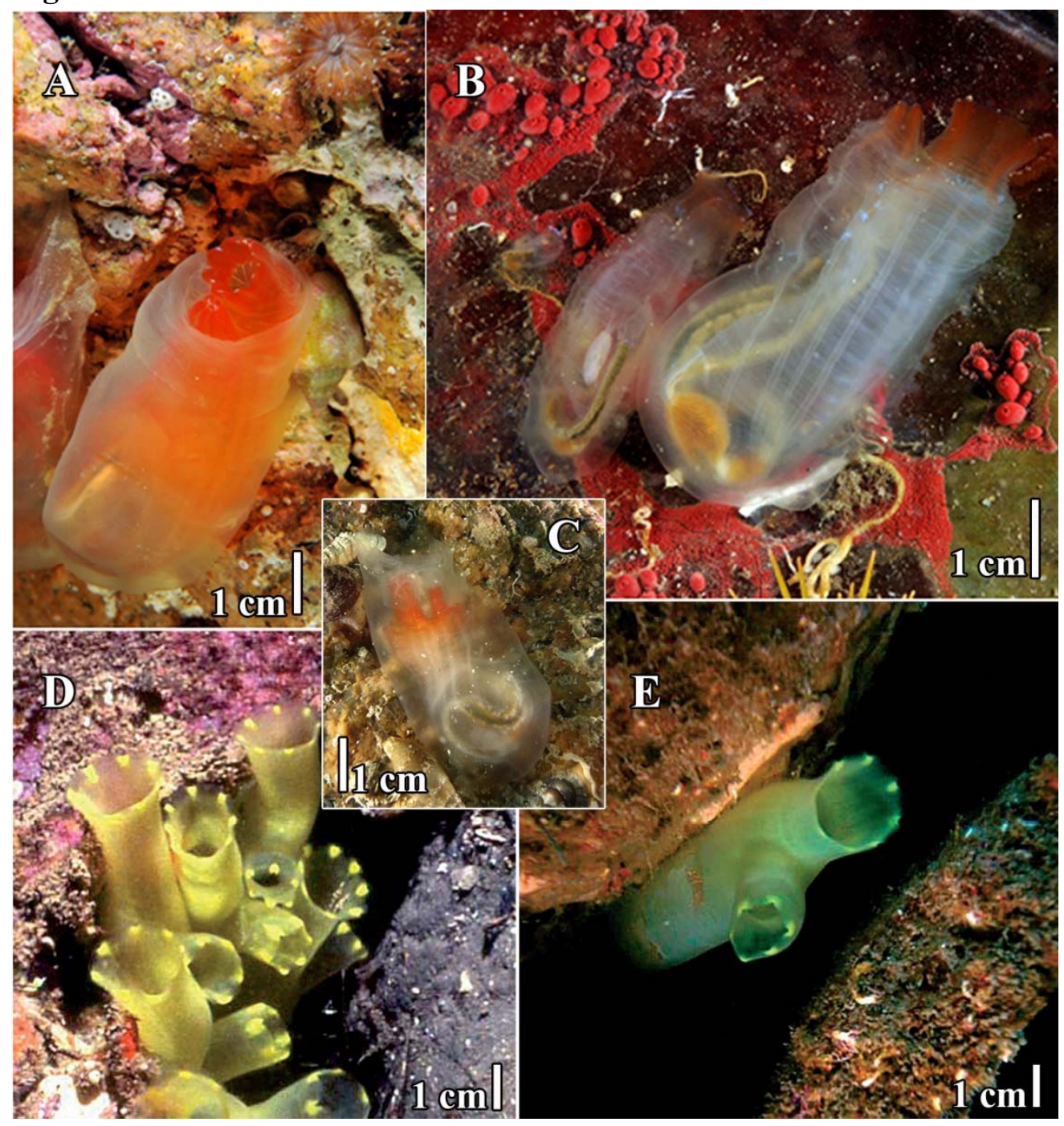

Figure 1. (A-C) Several living specimens of $C$. intermedia photographed and collected along the coasts of Olbia (Sardinia, Tyrrhenian Sea, Italy). (D-E) Living specimens of C. edwardsi with the typical sulphur-yellow appearance, photographed along Ligurian coasts (Mastrototaro \& Relini, 2011). 


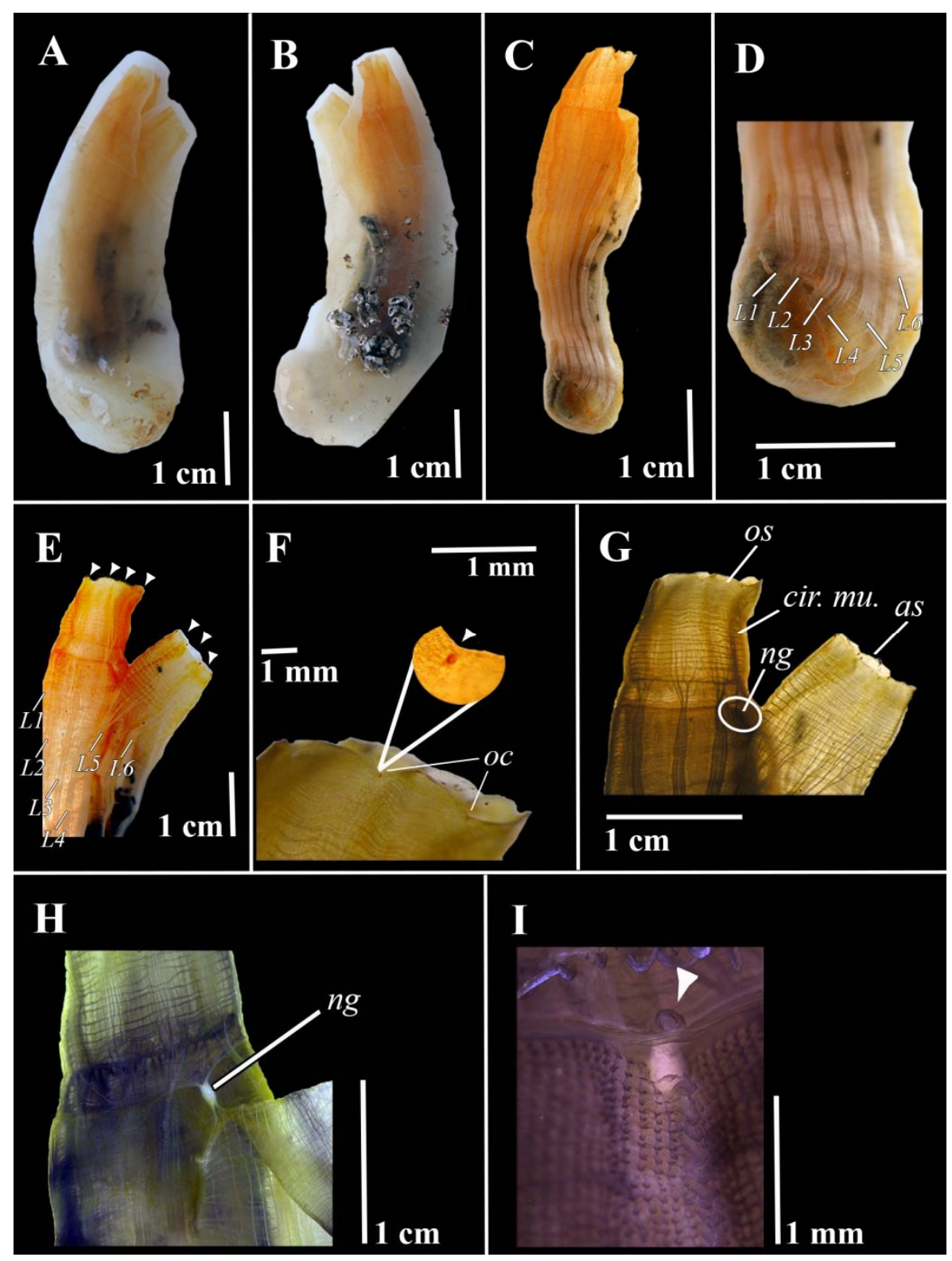

Figure 2. Ciona intermedia. (A) Left side of a specimen with the tunic. (B) Right side of a specimen with the tunic. (C) Specimen without the tunic, showing the six longitudinal muscle bands. (D) Magnification of the base of a specimen, white bars indicate the six longitudinal muscle bands (L1-L6). (E) Oral and atrial siphons with eight and six lobes, respectively (white arrows) and longitudinal muscle bands at the level of the siphons (L1-L6). (F) Red ocelli at the base between each lobe with the magnification of one red ocellus. (G) Oral and atrial siphons, with circular muscle systems, and the neural ganglion encircled in white. (H) Neural ganglion lying at the base of the oral and atrial siphons. (I) Magnification of the anterior region with dorsal tubercle (arrow). Abbreviations: as, atrial siphon; cir. mu., circular muscles; ng, neural ganglion; oc, ocellus; os, oral siphon. 


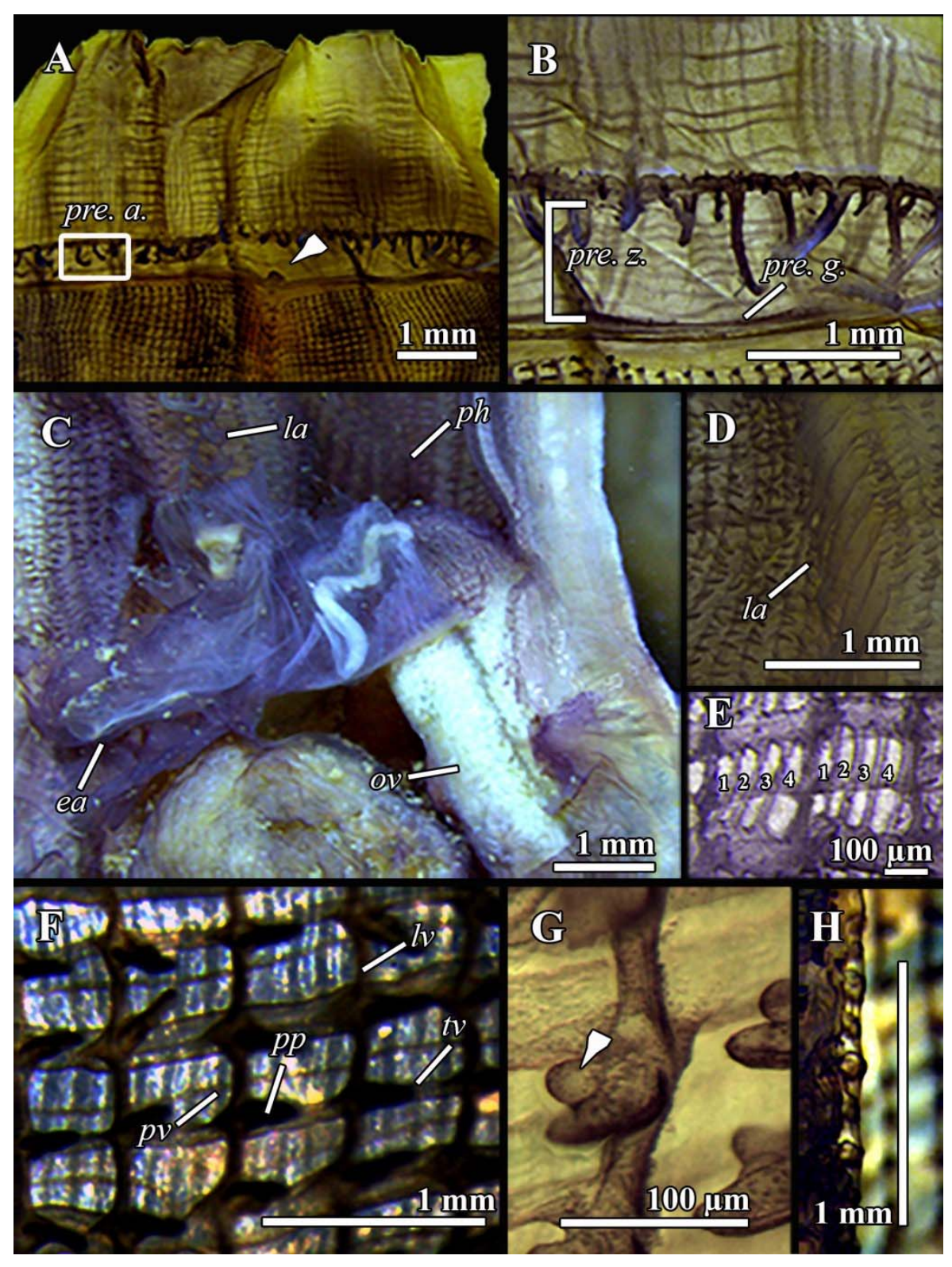

Figure 3. Ciona intermedia. (A) Prepharyngeal area (pre. a.), the white arrow indicates the dorsal tubercle. (B) Magnification of the prepharyngeal area with a wide prepharyngeal zone (pre. z.) and a narrow prepharyngeal groove (pre. g.), oral tentacles are clearly visible. (C) Bottom of the pharynx of a dissected specimen, with the white bar indicating the endostylar appendix. (D) Dorsal lamina with languets. (E) Magnification of the mesh of stigmata, with 4 stigmata per mesh (1-4). (F) Magnification of the branchial wall with the papillae placed at the intersection between the transverse vessels and the longitudinal vessels. Stigmata crossed by a narrow parastigmatic vessel. (G) Magnification of the papillae, white arrow showing the notch. (H) Section of the flat branchial wall. Abbreviations: ea, endostylar appendix; la, languet; lv, longitudinal vessel; ov, ovary; ph, pharynx; pre. a., prepharyngeal area; pre. g., prepharyngeal groove; pre. z., prepharyngeal zone; pp, papilla; pv, parastigmatic vessel; tv, transverse vessel. 


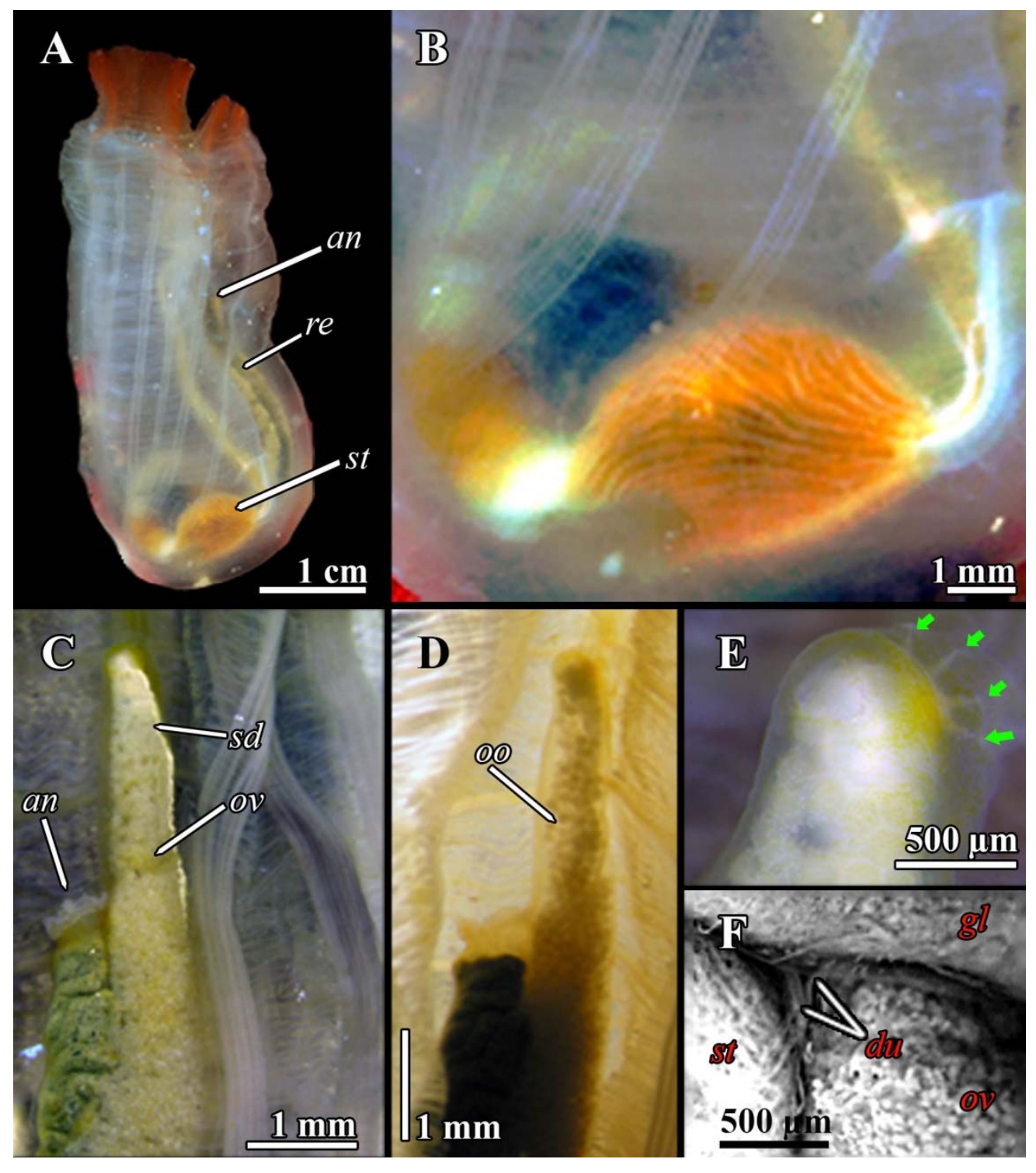

Figure 4. Ciona intermedia. (A) Living specimen with orange stomach. (B) Stomach with about 40 irregular broken folds on its surface. (C) Magnification of the ovary and lobed anus. (D) Ovary with numerous oocytes. (E) Magnification of the end of the gonoduct apertures showing the orange-yellow pigments and the four visible papillae at the distal end of the spermiduct (green arrows). (F) Magnification of the abdominal region showing testis follicles between stomach and the posterior gut loop forming two ducts that join in a single spermiduct at the level of the ovary. Abbreviations: an, anus; du, collecting ducts of the testis; gl, gut loop; oo, oocytes, ov, ovary; re, rectum; sd, spermiduct; st, stomach. 


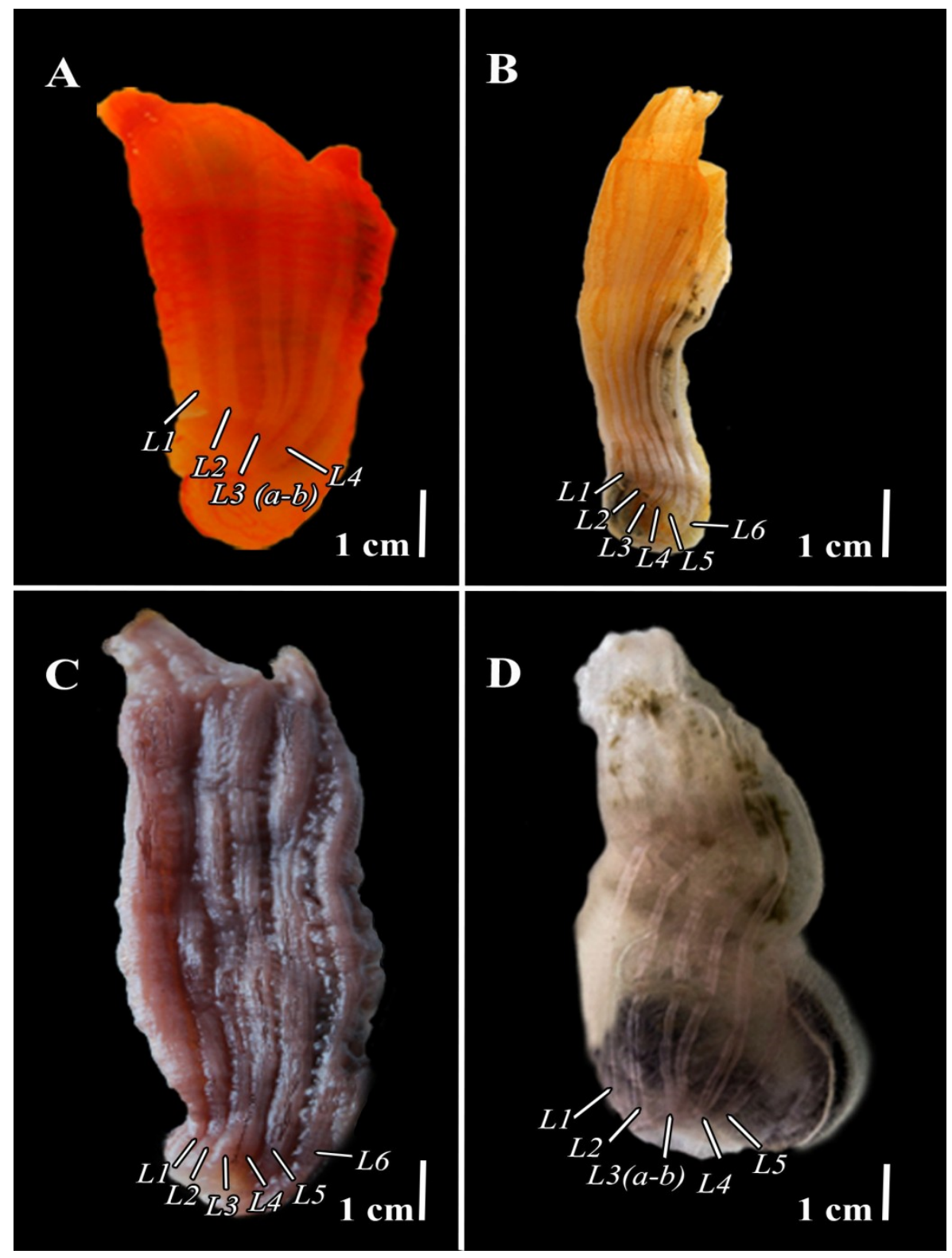

Figure 5. Comparison plate between four Ciona species, with bars highlighting the number of muscle bands. (A) Ciona roulei (courtesy of Marie Nydam) (B) Ciona intermedia collected in Olbia (Sardinia, Italy). (C) Ciona edwardsi collected in Sorrento, Tyrrhenian Sea by Mastrototaro F. (D) Ciona robusta collected along the coasts of Taranto, Ionian Sea (Mastrototaro et al., 2008). 

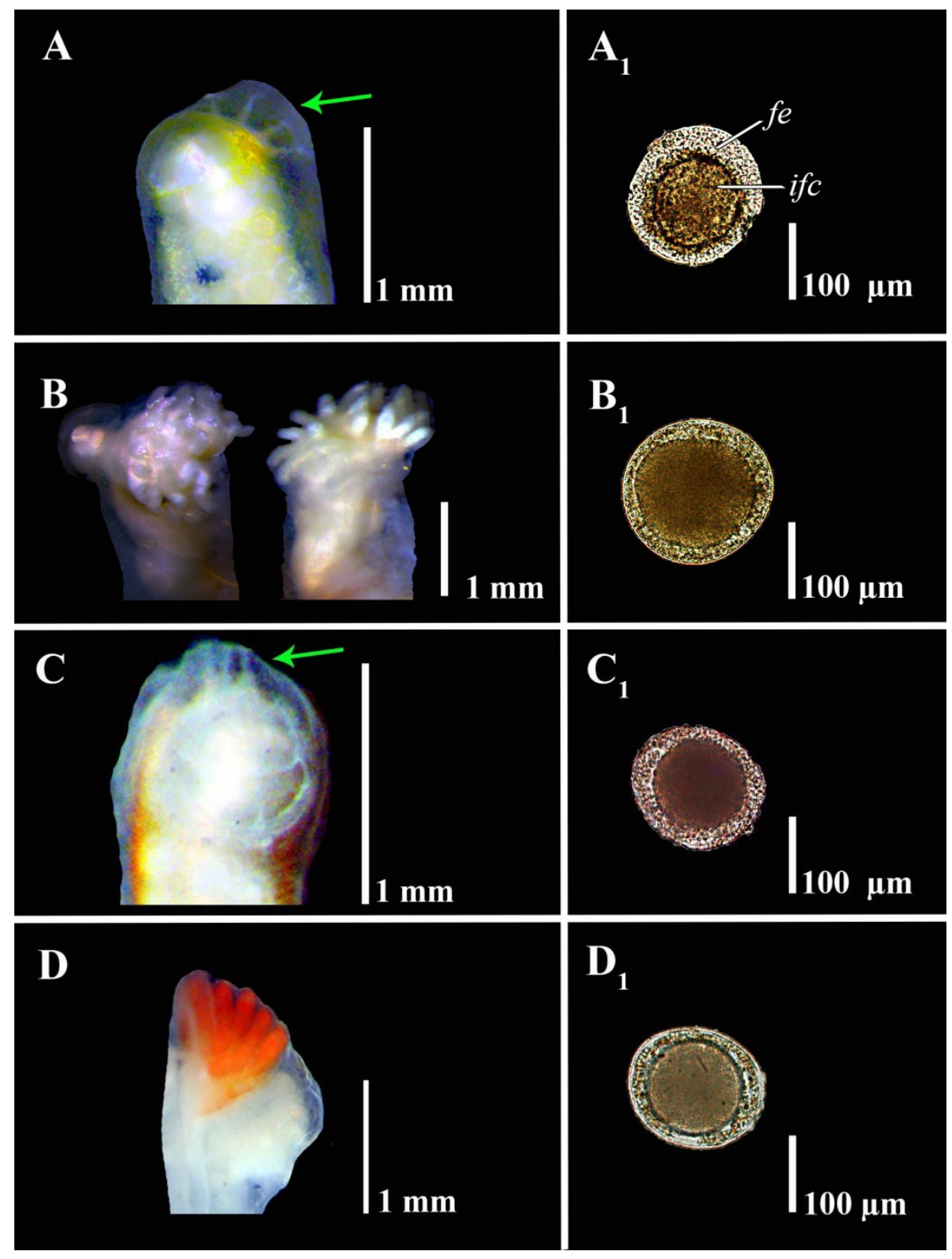

Figure 6. Comparison plate between spermiduct ends and oocytes of four Ciona species: $\left(\mathrm{A}-\mathrm{A}_{1}\right)$ Ciona intermedia, spermiduct with four visible papillae (green arrow), oocyte of about $100 \mu \mathrm{m}$ and a large outer follicular envelope. (B-B ${ }_{1}$ ) Ciona edwardsi, lateral and back view of the spermiduct with numerous papillae and oocyte larger in size than the oocytes found in the other three species. $\left(\mathrm{C}-\mathrm{C}_{1}\right)$ Ciona intestinalis, spermiduct with white papillae (green arrow), oocyte of about $100 \mu \mathrm{m}$. (D-D D $_{1}$ Ciona robusta, spermiduct with ellipsoidal red papillae, oocyte of about $100 \mu \mathrm{m}$. Abbreviations: fe, follicular envelope; ifc, inner follicle cells. 


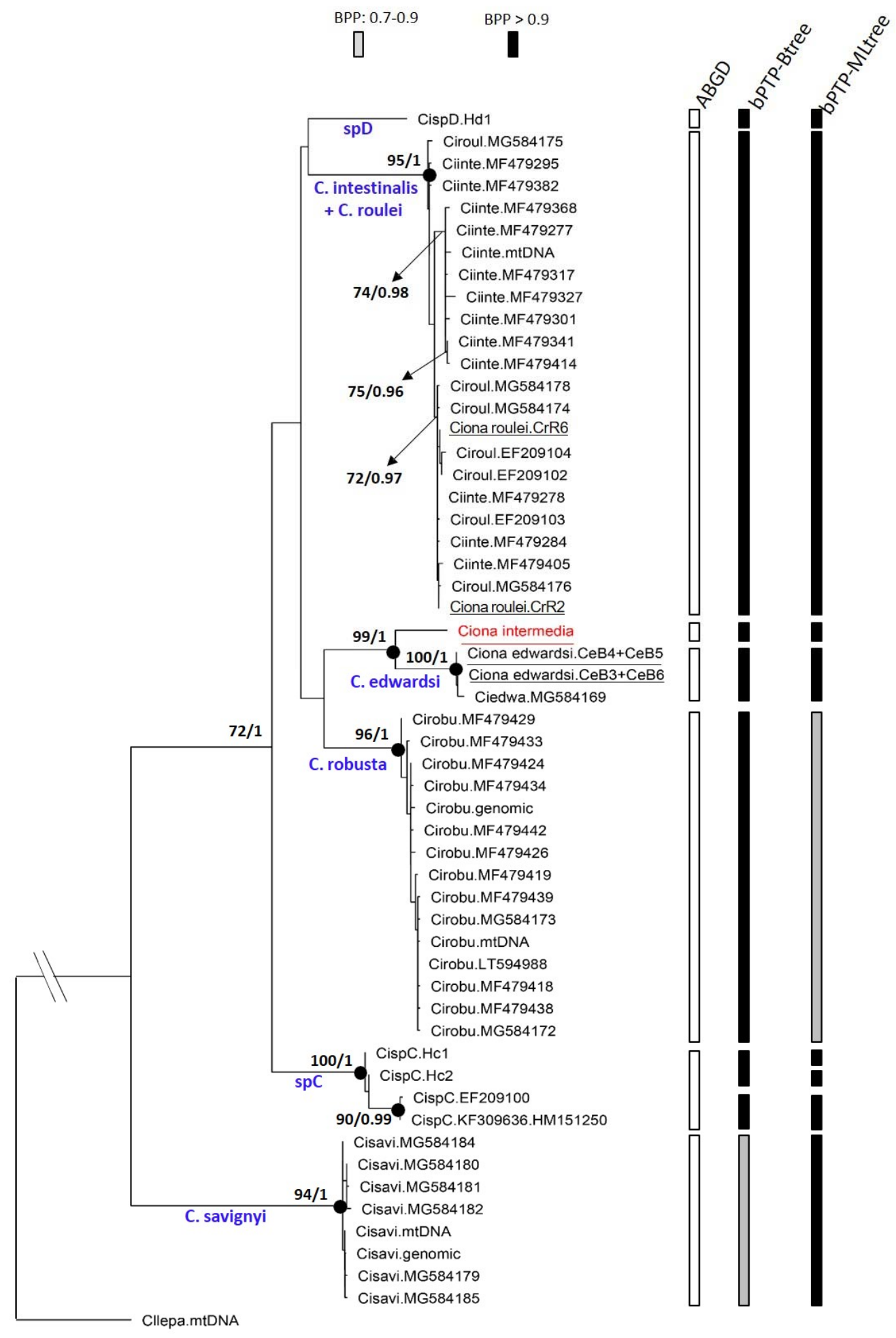

Figure 7. Maximum Likelihood tree based on the COI-1.2kb fragment, with mapping of the OTUs identified by the ABGD and bPTP analyses (vertical bars). Branch length is proportional to the number of substitutions per sites. Values close to the nodes are ML bootstrap percentage/BPP, and are shown only when both bootstrap $\geq 70 \%$ and $\mathrm{BPP} \geq 0.90$. Black dots: nodes having both bootstrap support $\geq 90 \%$ and $\mathrm{BPP} \geq 0.99$; underlining: sequences obtained in this study; ABGD: OTUs consistently identified by the 72 ABGD analyses detailed in Supplementary Table S5; bPTP-Btree: bPTP performed on the Bayesian tree; bPTP-MLtree: bPTP performed on the ML tree. Clavelina lepadiformis (Cllepa.mtDNA) was used as outgroup. Acronyms: Ciinte = Ciona intestinalis; Cirobu $=$ Ciona robusta Cisavi $=$ Ciona savignyi; Ciroul= Ciona roulei; Ciedwa=Ciona edwardsi; CispC $=$ Ciona $\mathrm{spC} ;$ CispD = Ciona spD. Analyzed sequences are listed in Supplementary Table S2. 


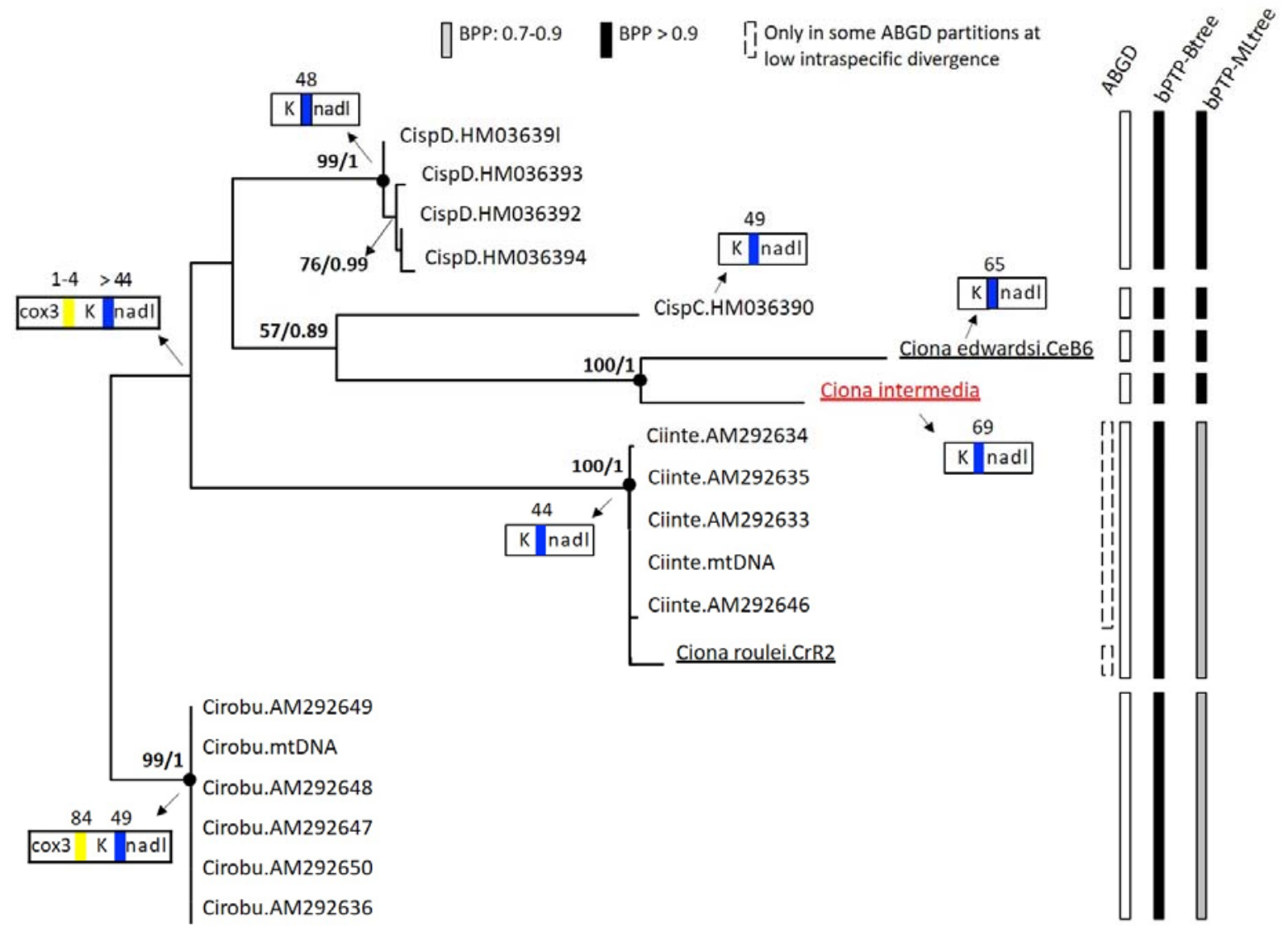

Figure 8. Maximum Likelihood tree based on the $x 3 n 1$ fragment, with diagram of the gene content of the $x 3 n 1$ fragment, and mapping of the OTUs identified by ABGD and bPTP analyses (vertical bars). Branch length is proportional to the number of substitutions per sites. Values close to the nodes are ML bootstrap percentage/BPP and are reported only when $>50 / 0.50$. Blue and yellow boxes in the gene content diagram: non coding spacers, with length in bp; K: gene trnK; black dots: nodes having both bootstrap support $\geq 90 \%$ and BPP > 0.99; underlining: sequences obtained in this study; ABGD: OTUs identified by the 18 ABGD analyses detailed in Supplementary Table S5, with dashed bars indicating some recursive partitions at the lowest intraspecies divergence; bPTP-Btree: bPTP performed on the Bayesian tree; bPTP-MLtree: bPTP performed on the ML tree. Species codes as in Figure 7. Analyzed sequences are listed in Supplementary Table S4. 


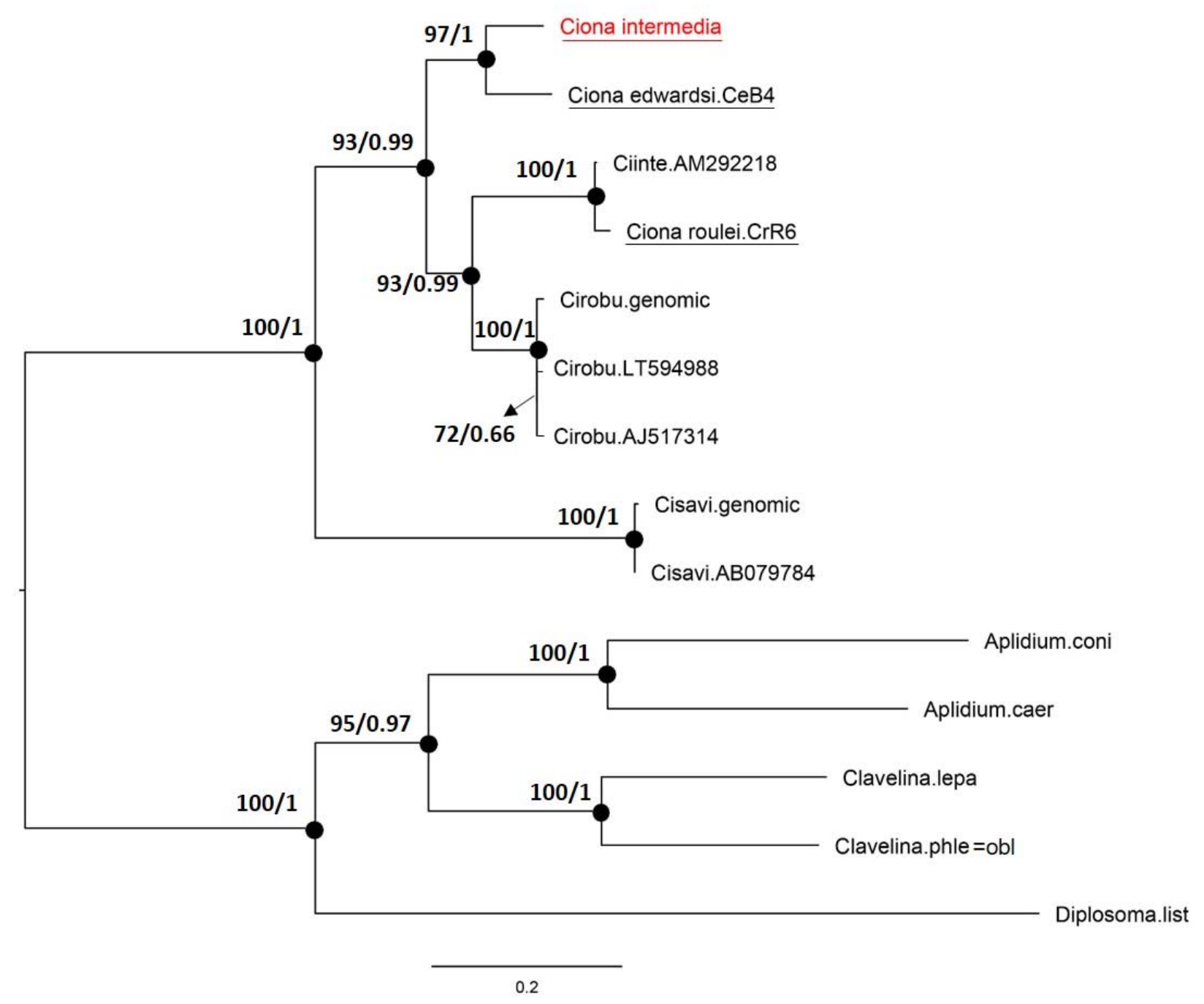

Figure 9. Maximum Likelihood based on the $\mathrm{x} 2 \mathrm{cb}$ fragment, consisting of the partial sequences of the cox 2 and $c o b$ gene. Branch length is proportional to the number of substitutions per sites. Values close to the nodes are ML bootstrap percentage/BPP. Black dots: nodes having both bootstrap support $\geq 90 \%$ and BPP $\geq 0.99$; underlining: sequences obtained in this study. Five Aplousobranchia species were used as outgroups: Aplidium conicum (Aplidium.coni), Aplidium coeruleum (Aplidium.caer), Diplosoma listerianum (Diplosoma.list), Clavelina lepadiformis (Clavelina.lepa) and Clavelina phlegraea, a junior synonym of Clavelina oblonga (Clavelina.phle=obl) (Ordóñez et al., 2016). Other species codes as in Figure 7. Analyzed sequences are listed in Supplementary Table S3 
